\title{
HCCI in a CFR Engine: Experiments and Detailed Kinetic Modeling
}

\author{
Daniel Flowers, Salvador Aceves, Ray Smith \\ Lawrence Livermore National Laboratory \\ John Torres, James Girard, Robert Dibble \\ University of California, Berkeley
}

This paper was prepared for submittal to

Society of Automotive Engineers 2000 World Congress,

March 6-9, 2000, Detroit, Michigan

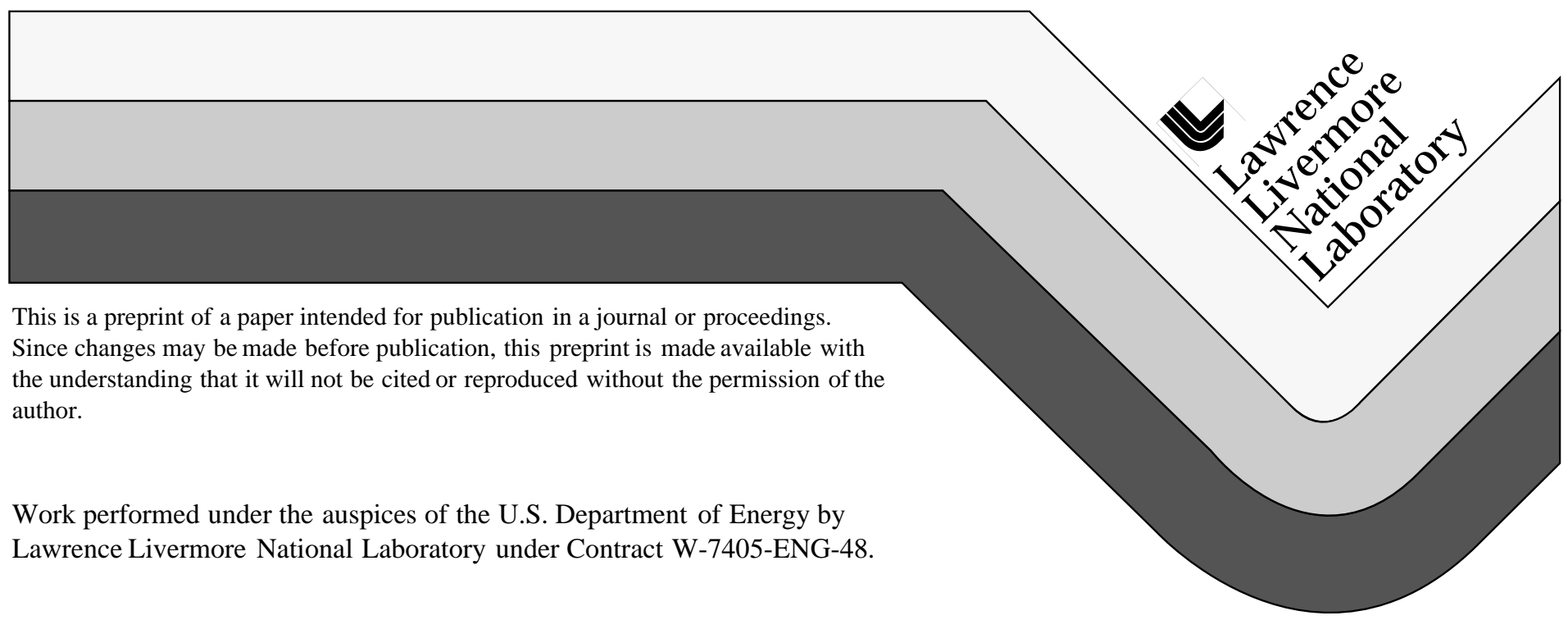




\section{DISCLAIMER}

This document was prepared as an account of work sponsored by an agency of the United States Government. Neither the United States Government nor the University of California nor any of their employees, makes any warranty, express or implied, or assumes any legal liability or responsibility for the accuracy, completeness, or usefulness of any information, apparatus, product, or process disclosed, or represents that its use would not infringe privately owned rights. Reference herein to any specific commercial product, process, or service by trade name, trademark, manufacturer, or otherwise, does not necessarily constitute or imply its endorsement, recommendation, or favoring by the United States Government or the University of California. The views and opinions of authors expressed herein do not necessarily state or reflect those of the United States Government or the University of California, and shall not be used for advertising or product endorsement purposes. 


\title{
HCCI In A CFR Engine: Experiments And Detailed Kinetic Modeling
}

\author{
Daniel Flowers, Salvador Aceves, Ray Smith \\ Lawrence Livermore National Laboratory \\ John Torres, James Girard, Robert Dibble \\ University of California Berkeley
}

\begin{abstract}
Single cylinder engine experiments and chemical kinetic modeling have been performed to study the effect of variations in fuel, equivalence ratio, and intake charge temperature on the start of combustion and the heat release rate. Neat propane and a fuel blend of $15 \%$ dimethyl-ether in methane have been studied. The results demonstrate the role of these parameters on the start of combustion, efficiency, imep, and emissions. Single zone kinetic modeling results show the trends consistent with the experimental results.
\end{abstract}

\section{INTRODUCTION}

Homogeneous Charge Compression Ignition ( $\mathrm{HCCl})$ engines are being considered as a future replacement for diesel engines. $\mathrm{HCCl}$ engines have the potential for high efficiency (diesel-like; [1]), very low oxides of nitrogen $\left(\mathrm{NO}_{\mathrm{x}}\right)$ and particulate emissions, and possibly lower cost (because no high-pressure injection system is required). Disadvantages of $\mathrm{HCCl}$ engines are: high hydrocarbon (HC) and carbon monoxide (CO) emissions, high peak pressures, high rates of heat release, reduced operating range, lower maximum power, difficulty in starting the engine, and difficulty of control.

$\mathrm{HCCl}$ was identified as a distinct combustion phenomenon about 20 years ago. Initial papers recognized the basic characteristics of $\mathrm{HCCl}$ that have been validated many times since then: $\mathrm{HCCl}$ ignition occurs at many points simultaneously, with no flame propagation [2][3]. Combustion was described as very smooth, with very low cyclic variations. Noguchi et al. also conducted a spectroscopic study of $\mathrm{HCCl}$ combustion [3]. Many radicals were observed, and they were shown to appear in a specific temporal sequence. In contrast, with spark-ignited (SI) combustion all radicals appear at the same time (probably distributed in the same spatial sequence through the flame front).
These initial experiments were done in 2-stroke engines, with very high rates of EGR.

Since then, $\mathrm{HCCl}$ two-stroke engines have been developed to the point of commercialization for motorcycles [4]. $\mathrm{HCCl}$ motorcycle engines have higher fuel economy, lower emissions and smoother combustion than 2-stroke spark-ignited engines. However, $\mathrm{HC}$ and $\mathrm{CO}$ emissions out of the $\mathrm{HCCl}$ engine are still very high compared with the current automotive emissions standards. An improved version of the engine has been recently evaluated, which shows improvements in fuel economy and emissions [5].

Najt and Foster did the first $\mathrm{HCCl}$ experiment with a fourstroke engine [6]. They also analyzed the process, considering that $\mathrm{HCCl}$ is controlled by chemical kinetics, with no influence from physical effects (turbulence, mixing). Najt and Foster used a simplified chemical kinetics model to predict heat release as a function of pressure, temperature, and species concentration in the cylinder.

A description of the $\mathrm{HCCl}$ process has gained acceptance: $\mathrm{HCCl}$ has been described as purely controlled by chemical kinetics, with little effect of turbulence. Crevices and boundary layers are too cold to react, and result in hydrocarbon and $\mathrm{CO}$ emissions. Combustion at homogeneous, low equivalence ratio conditions results in modest temperature combustion products, containing very low concentrations of $\mathrm{NO}_{x}$ and particulate matter.

Physical understanding has not resulted in a solution to the problems of operating a four-stroke engine in $\mathrm{HCCl}$ mode. The control issue appears to be most important. Some alternatives have been described [7][8], but further research is required to identify a general control strategy.

Simulation of $\mathrm{HCCl}$ engines is not well developed, even though the process may be reasonably well understood. 
Most publications on $\mathrm{HCCl}$ present only experimental results. Of those that present analysis, some have used a fluid mechanics code [9] with a very simplified chemical kinetics model. The use of fluid mechanics codes is appropriate in operating conditions such as PREDIC (early direct injection; [10]), where the charge is not homogeneous and fuel mixing and evaporation may have a significant effect on the combustion process. However, for homogeneous charge engines, the process is mainly dominated by chemistry, and it is more important to have a detailed chemical kinetics model than a fluid mechanics model. Valuable predictions and results can be obtained from single-zone chemical kinetics simulations that assume that the combustion chamber is a well-stirred reactor with uniform temperature and pressure [11][12][13]. This is the tool used in this paper. The ideal tool for $\mathrm{HCCl}$ analysis is a combination of a fluid mechanics code with a detailed chemical kinetics code. A hybrid method using a 10zone chemical kinetics simulation of an engine using KIVA to predict the in cylinder temperature distribution has shown promising results for modeling the $\mathrm{HCCl}$ combustion process, including accurate prediction of peak pressure, burn duration, hydrocarbon and carbon monoxide emissions [14].

A key to practical implementation of the $\mathrm{HCCl}$ concept in an engine is developing methods to control combustion timing. Control methods must be designed to adjust the heat release process to occur at the appropriate time in the engine cycle. In this research, single cylinder engine experiments and chemical kinetic simulations are applied to study the effect of variation in fuel, equivalence ratio, and intake temperature on ignition timing. The intent of this paper is to provide some further insight into the control of $\mathrm{HCCl}$ combustion. The data demonstrates some of the operational issues that need to be addressed.

\section{SINGLE CYLINDER HCCI EXPERIMENTS}

Experiments have been performed on a single cylinder Cooperative Fuels Research (CFR) engine modified for $\mathrm{HCCl}$ operation. The engine is naturally aspirated and an intake manifold heater has been installed to allow for preheating the intake air. The engine characteristics and operating parameters used in these experiments are listed in Table 1. Neat propane and a blend of $15 \%$ (by volume) dimethyl-ether (DME) in methane are the fuels tested. These tests have been designed to characterize the operating parameters that influence $\mathrm{HCCl}$ engine emissions and performance. The fuel, intake-air temperature, and equivalence ratio are varied in these experiments.

Testing was also conducted with neat methane fuel, but stable $\mathrm{HCCl}$ operation was only achieved for one operating point at the limit of preheating capacity. Operation in $\mathrm{HCCl}$ mode with pure methane was achieved initially using blend of methane and DME. The flow rate of each fuel was independently controlled and once stable operation was achieved, the DME flow rate was gradually reduced to zero flow.

Tab le 1 - CFR engine geometry and operating parameters

\begin{tabular}{|l|r|}
\hline Displacement & $0.612 \mathrm{~L}$ \\
\hline Bore & $8.25 \mathrm{~cm}$ \\
\hline Stroke & $11.4 \mathrm{~cm}$ \\
\hline Connecting Rod Length & $25.4 \mathrm{~cm}$ \\
\hline Compression Ratio & $16: 1$ \\
\hline Engine Speed & $1800 \mathrm{RPM}$ \\
\hline
\end{tabular}

The CFR engine has been fitted with an Optrand AutoPSI-S (200 bar full-scale range) combustion pressure sensor. The signal is acquired with a National Instruments PCl-6110E data acquisition (four input channels with a 5 mega-sample per second per channel maximum acquisition rate) board in a Windows NT system. The pressure is acquired at every 0.1 crank angle degrees (CAD) using a 3600/rev crankshaft encoder. Significant noise was present in the acquired pressure data despite extensive efforts to eliminate it. An eighth-order Butterworth digital low pass filter has been used to filter the raw pressure data in post-processing. The raw pressure signal is filtered forward and backward to eliminate any phase shift. The pressure data is filtered, and then averaged. The rate of heat release was calculated from the average pressure trace by a published method [15].

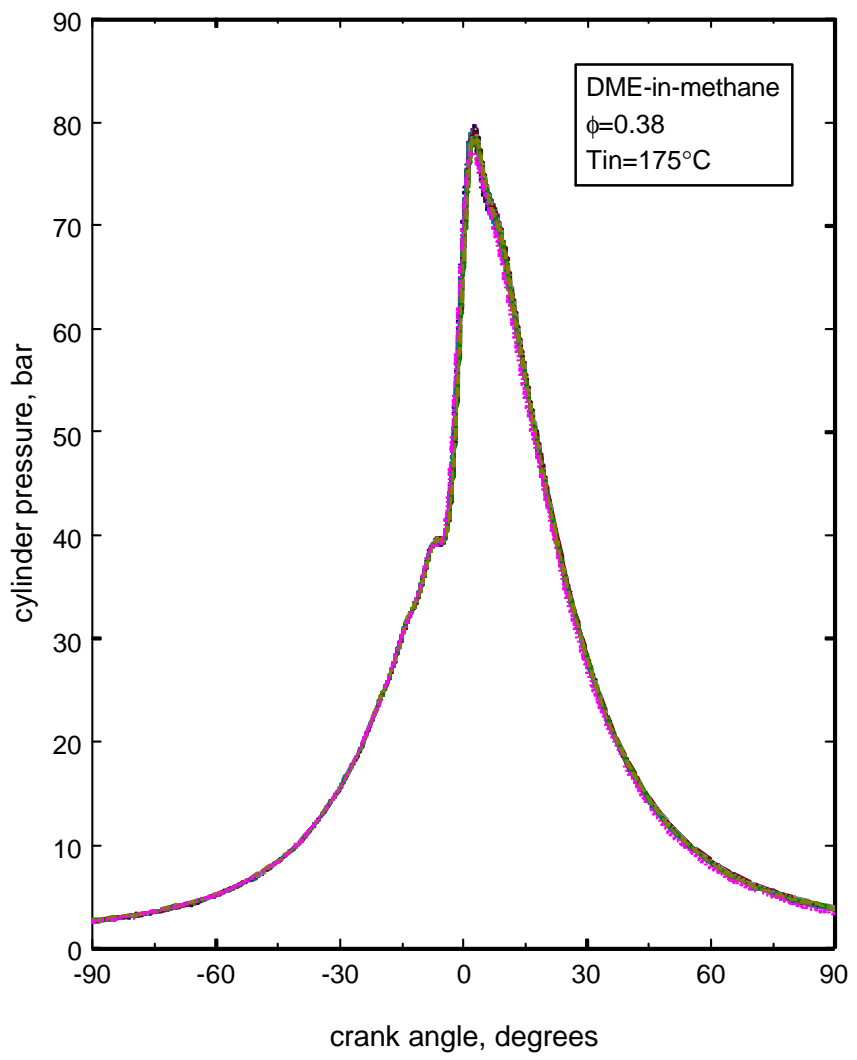

Figure 1 - Multiple instantaneous pressure versus crank angle traces for a typical experimental $\mathrm{HCCl}$ operating point on propane 
Propane and the DME-in-methane blend have similar characteristics in an $\mathrm{HCCl}$ engine cycle, exhibiting cool flame heat release. These low-temperature reactions increase charge temperature (and generate a radical pool initiating further chemical reactions) as the charge is compressed. Neat methane has very little cool flame chemistry causing the greater difficulty achieving conditions for autoignition in an engine cycle relative to the other fuels.

Figure 1 shows typical pressure traces for $\mathrm{HCCl}$ operation of the CFR. The figure also shows several overlaid pressure traces that demonstrate the low cycleto-cycle variation in $\mathrm{HCCl}$ operation. This data is filtered at a cutoff frequency of around $3 \mathrm{kHz}$. This cutoff frequency was selected because it minimized the noise in the calculation of the rate of heat release without compromising the pressure trace. The analyses of all of the experimental pressure traces were performed on data filtered with this cutoff frequency. This cutoff frequency does eliminate the acoustic "knock" signal from the pressure trace, but allowing higher frequencies led to significant propagation of noise into the calculation of heat release rate.

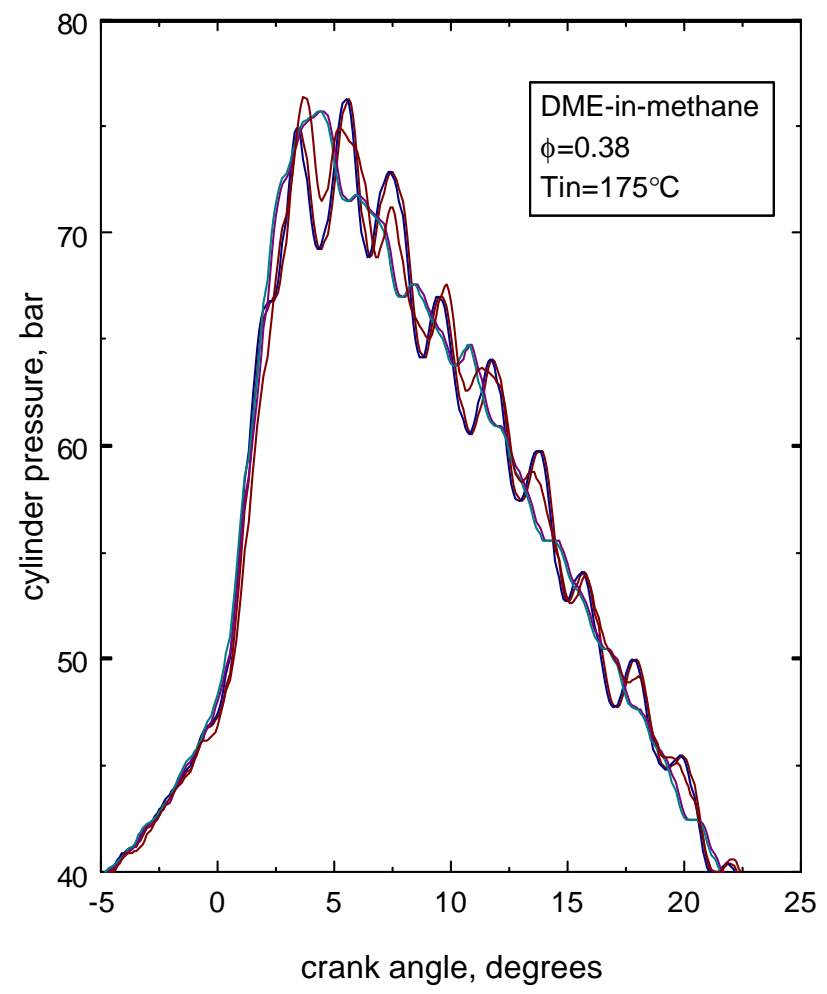

Figure 2 - Overlay of several instantaneous pressure versus crank angle traces showing acoustic wave response

An acoustic wave phenomenon is generally present in the pressure traces. This knock-like pressure wave is fairly low amplitude, but Fourier analysis of the instantaneous pressure data shows that the frequency is consistent from cycle-to-cycle. Figure 2 shows a few instantaneous pressure traces at crank angles near the combustion event. This pressure data is filtered at a 10 $\mathrm{kHz}$ cutoff so that the knock frequency could be resolved. The frequency of roughly $5 \mathrm{kHz}$ near TDC corresponds to the expected knock frequency for this engine bore, $f=a /(2 B)$, where $f$ is frequency, $a$ is sound speed and $B$ is the engine bore. While the frequency of the wave is consistent the phasing of the pressure wave varies from cycle-to-cycle.

Figure 3 shows the rate of chemical heat release that has been estimated from the pressure trace for a typical cycle. The Woschni heat transfer correlation is used to estimate the wall heat transfer and thus to more accurately estimate chemical heat release [16]. Acoustic and electronic noise present in the pressure acquisition propagates significant noise in the heat release calculation. Numerical differentiation in the heat release calculation significantly amplifies the noise, but the main release of heat is sufficiently intense to be well characterized, despite the noise. In a practical engine a marker for the combustion timing is necessary for closed loop control. The peak value of the rate of heat release has been taken here to be the marker for the timing of the heat release event. This essentially corresponds to the peak pressure gradient and is easily identified. The performance data has been presented with respect to this parameter.

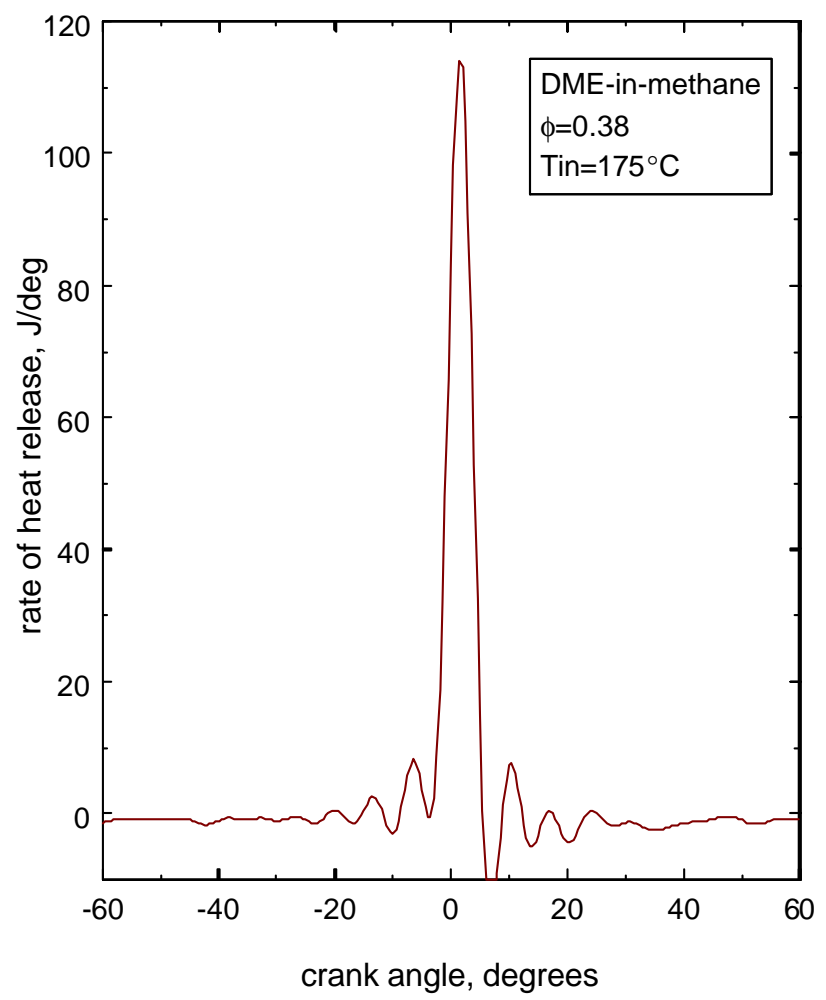

Figure 3 - Rate of heat release versus crank angle

Figures 4 and 5 show the intake equivalence ratio plotted against the peak of heat release for propane and the DME-in-methane blend. The intake equivalence ratio is determined using the measured flow rates of fuel 
and intake air. Each fuel has been operated at three different intake temperatures. The intake temperature is measured upstream of the intake valve, the charge temperature at intake valve closure is not known. Heat transfer and hot residuals affect the in cylinder temperature. The measured intake temperature should be considered only as a relative indicator of the charge air temperature at valve closure, because the true temperature could be higher or lower than this measured temperature. The relationship between equivalence ratio and crank angle for peak of heat release for these fuels is essentially monotonic. As equivalence ratio is increased the walls and residual gas are hotter resulting in earlier occurrence of the main autoignition event. Higher temperatures over the cycle lead to radical production at earlier crank angles. For an individual fuel, the curves appear to be consistent for each inlet temperature and shifted to lower equivalence ratio as temperature increases. This indicates that the higher temperature results in the radical production earlier in the cycle for the same equivalence ratio, as would be expected. The propane curves are much steeper than the DME-in-methane curves. This is likely due to the difference in chemistry between the fuels. The authors speculate the following: This difference in slope could be due to the decrease in the negative partial pressure coefficient of methane, which causes reduced reactivity as the partial pressure of methane increases. Also methane can tend to be a sink for radicals which could also reduce the slope of the equivalence ratio versus timing. For each intake temperature the lower limit of equivalence ratio is the lowest level at which stable operation could be achieved.

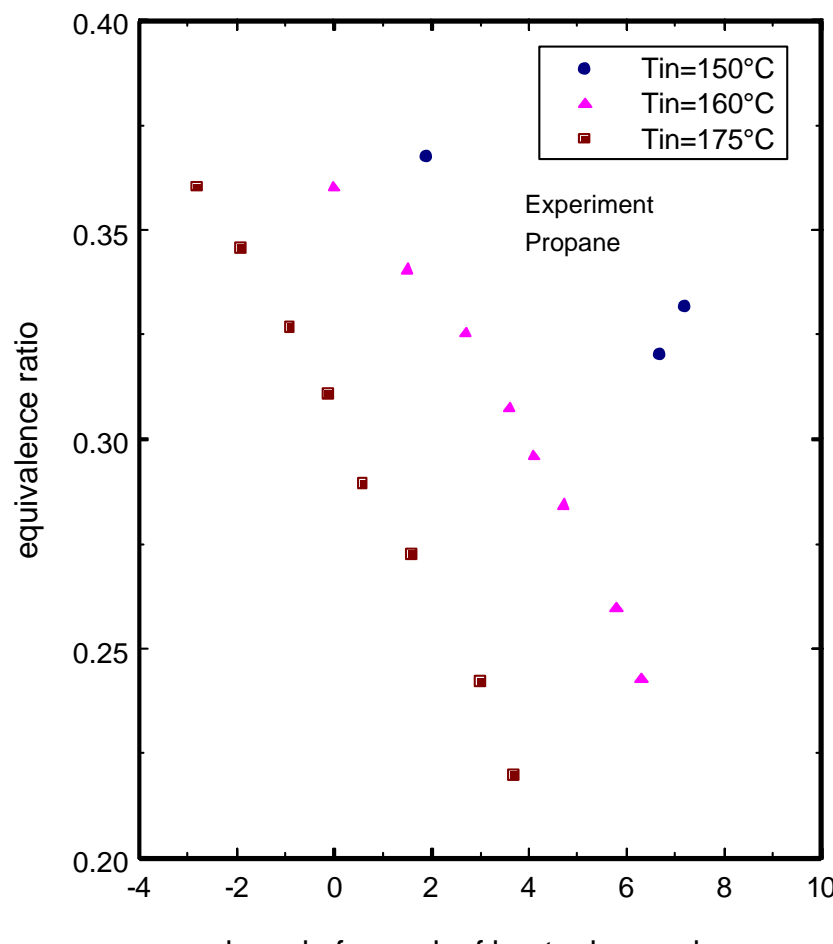

crank angle for peak of heat release, degrees

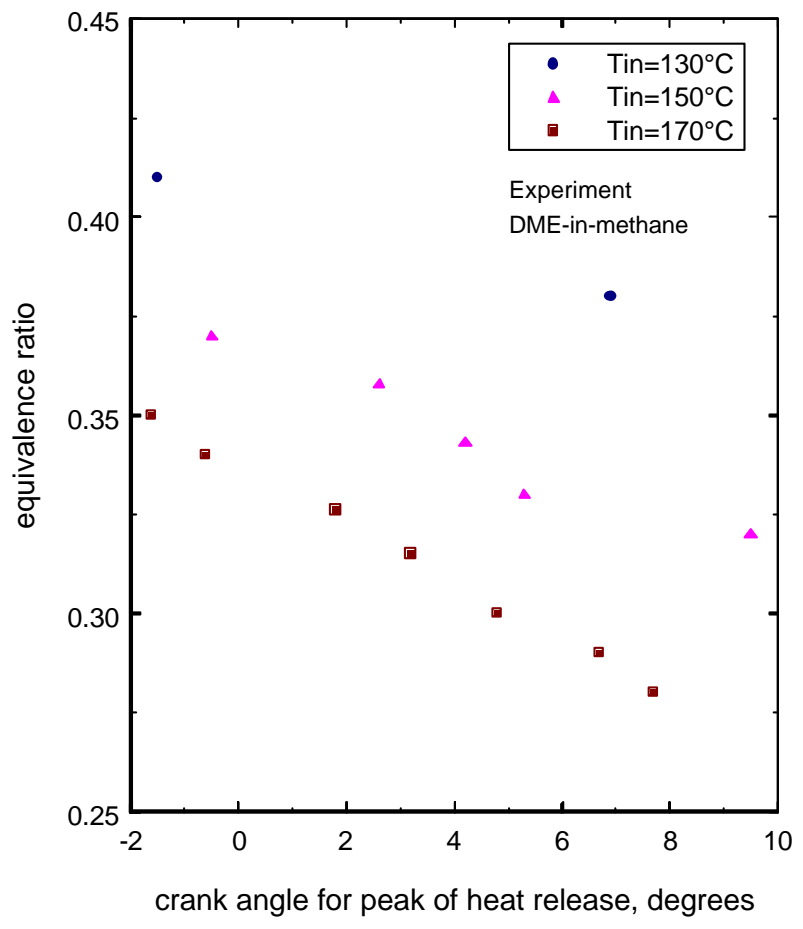

Figure 5 - experimental results of equivalence ratio versus timing for peak rate of heat release for DME-in-methane

Figures 6 and 7 show the peak cylinder pressure as a function of combustion timing. The trends shown for both fuels are consistent in that the peak pressure is relatively flat at peak of heat release near TDC and then decreases as the peak of heat release occurs later in the cycle. The peak pressure increases with decreasing temperature due to the higher volumetric efficiency at lower intake temperature.

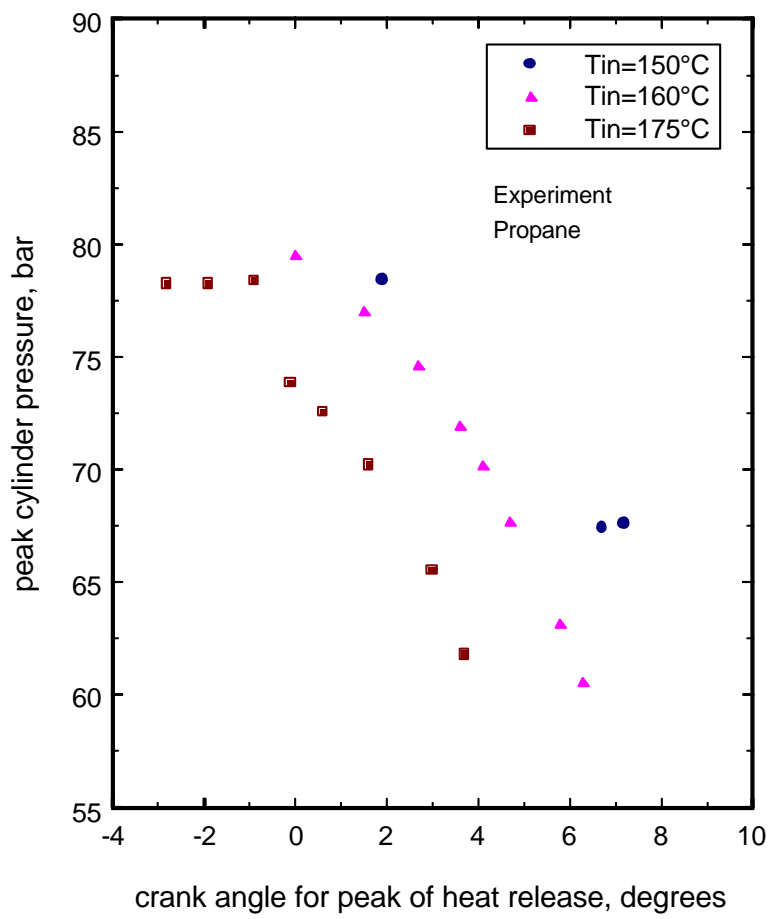

Figure 6 - experimental results of peak cylinder pressure versus peak rate of heat release for propane
Figure 4 - experimental results of equivalence ratio versus timing for peak rate of heat release for propane 


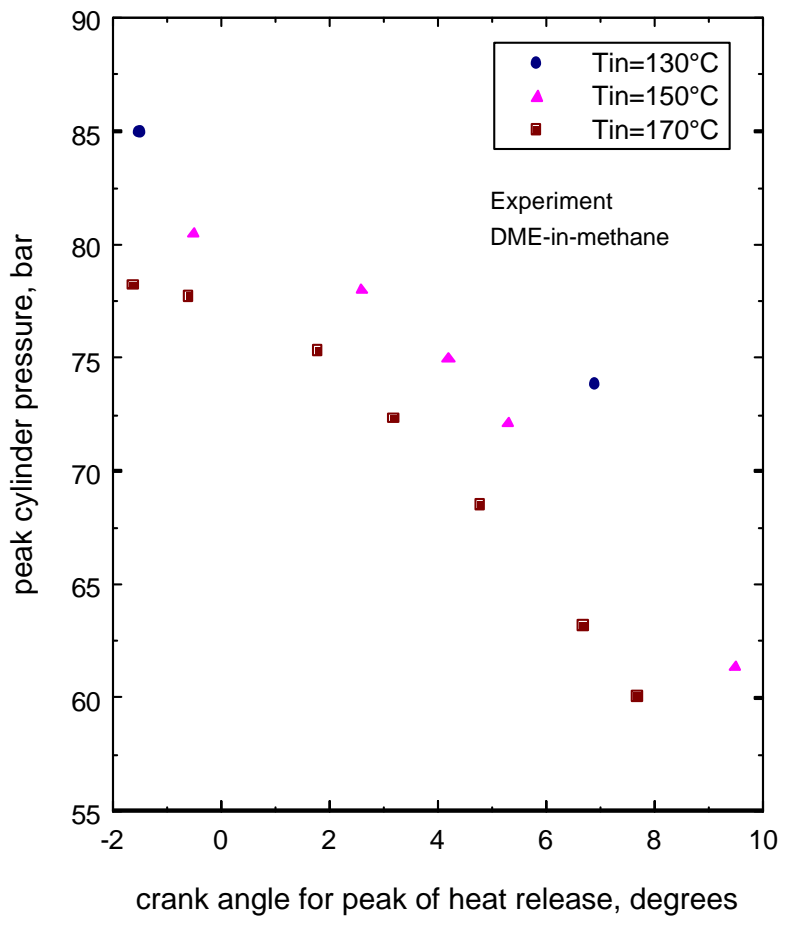

Figure 7 - experimental results of peak cylinder pressure versus peak rate of heat release for DME-in-methane

Figures 8 and 9 show burn duration versus timing for both fuels. The burn duration is defined as the crank angle difference between the occurrence of $10 \%$ of the peak value of rate of heat release on the rise and fall of the heat release curve (i.e. the crank angle width of the heat release rate curve). For propane, the burn duration increases smoothly as the timing moves later, ranging from roughly 7 to 9 crank angle degrees (CAD). Lower inlet temperature seems to reduce the burn duration for propane. For the same heat release timing, the equivalence ratio will be higher for lower inlet temperature. The higher equivalence ratio results in hotter walls, hotter residuals, and a larger pool of radicals yielding more rapid heat release. The DME-inmethane blend follows a similar trend in burn duration until the peak of heat release occurs at 7 CAD ATDC.

As combustion becomes later than this the burn duration jumps to 13-14 CAD. This discontinuity may be due to the kinetics of the dual fuel mixture. The heat release rate has a dual mode nature for this fuel blend. Chemical kinetic modeling shows that as the timing occurs later in the cycle the DME is almost entirely consumed before the methane begins to react. This lag in reactivity of the two components coupled with the expansion cooling could result in significant extension of the heat release. This will be further discussed in the modeling section.

Figures 10 and 11 show the indicated mean effective pressure (imep) versus crank angle for peak rate of heat release. The imep follows a fairly smooth trend with timing. The peak imep shifts with different intake conditions. For increasing intake temperature the timing of the peak imep can be seen to advance. With lower intake temperatures, the equivalence ratio required to achieve earlier combustion increases. A tradeoff between equivalence ratio and the timing of the pressure rise determine the peak imep. The reduction in overall imep with elevated intake temperature is due to reduction in volumetric efficiency. It should be noted that in this naturally aspirated, unthrottled engine, the imep at the lower limit of stable operation is 3-3.5 bar, depending on the fuel. In order to idle the engine, the available chemical energy in the cylinder must be reduced either by addition of residual gas or by throttling. Previous simulation of $\mathrm{HCCl}$ engine operation has demonstrated that residual gas addition may be an effective way of reducing output power for idle operation [13].

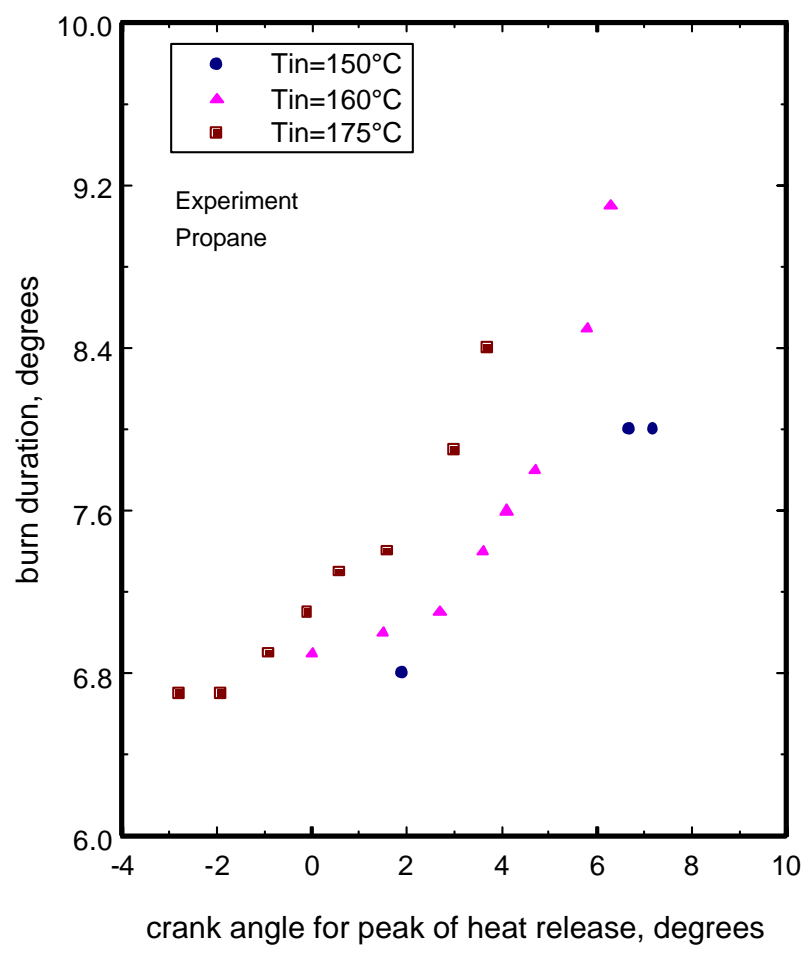

Figure 8 - experimental results of burn duration versus timing for peak rate of heat release for propane

Figures 12 and 13 show the gross indicated thermal efficiency versus timing of the peak of rate of heat release. The efficiency increases uniformly with later combustion timing. This is likely due to decreasing heat transfer with the lower temperatures occurring in later timed, higher equivalence ratio combustion. The efficiency varies significantly (from $32-45 \%$ ) with a relatively small change in the timing (12 CAD). This suggests that heat transfer becomes much greater as the equivalence ratio resulting in lower efficiency.

Figures 14 and 15 show the hydrocarbon emissions versus timing of peak heat release rate. The hydrocarbon emissions essentially increase linearly with later timing. The lower hydrocarbon emissions as combustion advances, despite the presence of more fuel, may be due to a variety of factors. The higher equivalence ratio mixture causes more rapid pressure 
rise during the autoignition process, resulting in a more of the charge reaching temperatures that promote ignition. The hydrocarbon reduction at higher equivalence ratio also may result from late hydrocarbon oxidation during the expansion stroke, also due to the higher overall temperature due to greater heat release at higher temperature. The energy released due to late hydrocarbon oxidation would do very little additional work on the piston.

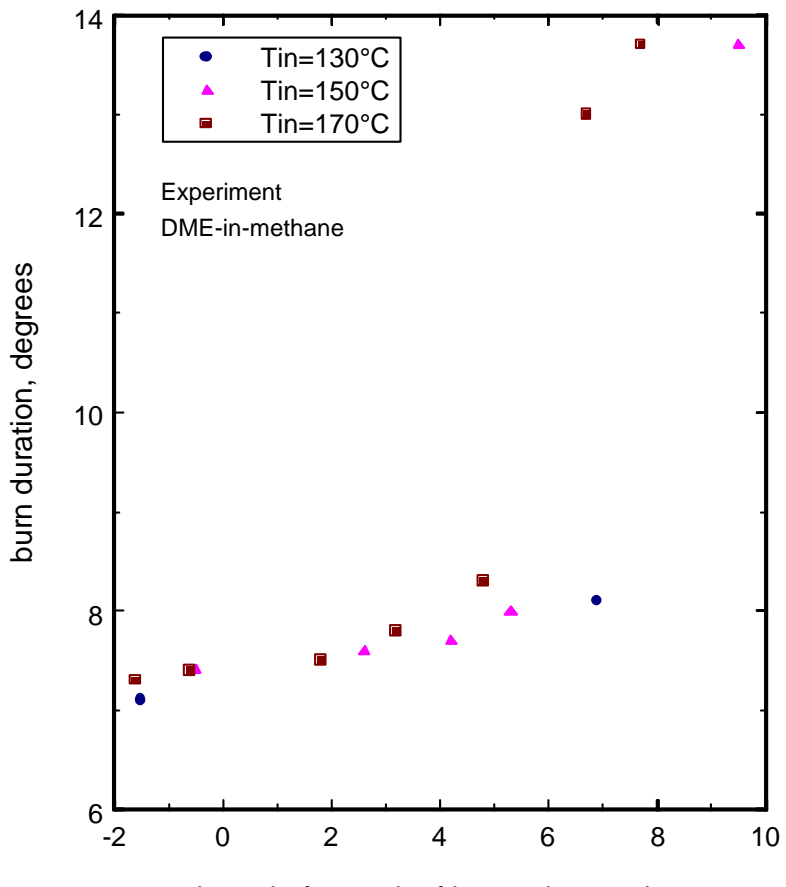

crank angle for peak of heat release, degrees

Figure 9 - experimental results of burn duration versus timing for peak rate of heat release for DME-in-methane

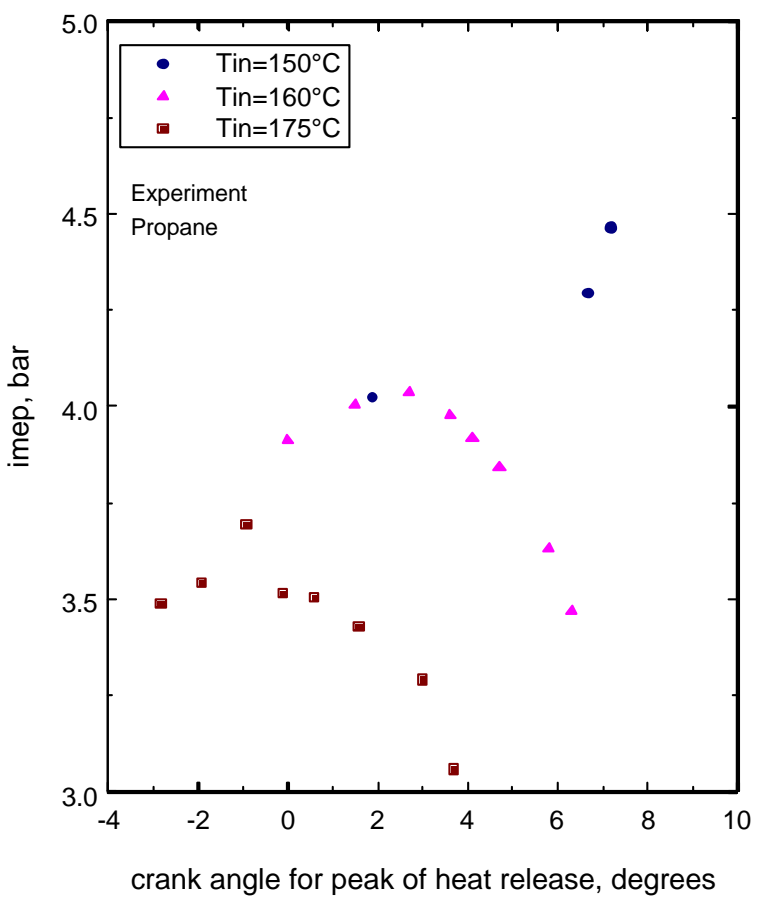

Figure 10 - experimental results of imep versus timing for peak rate of heat release for propane

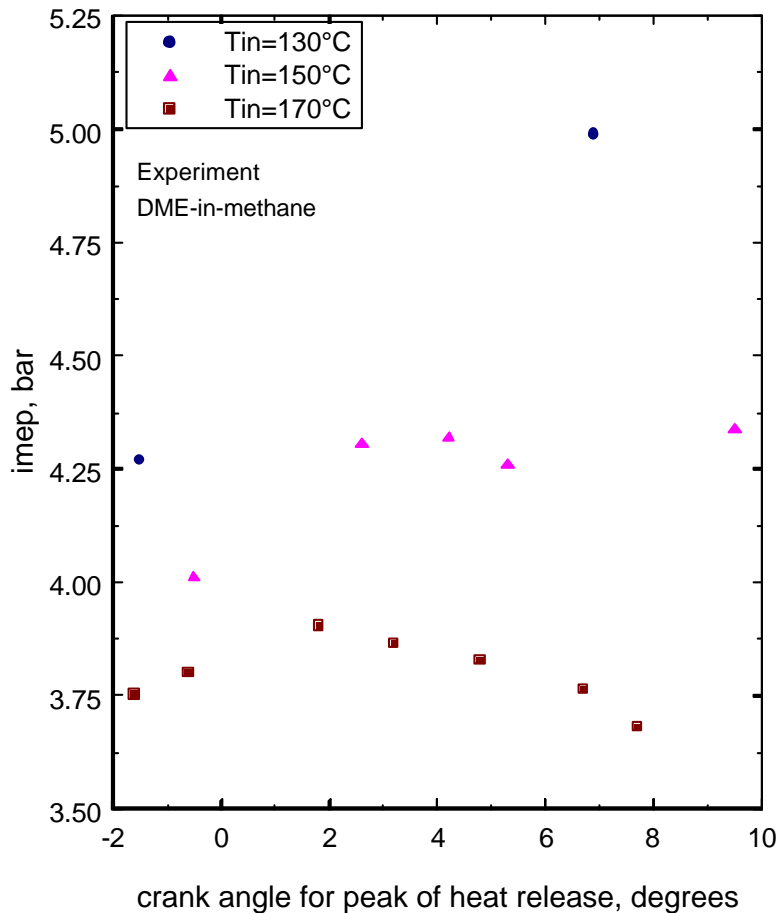

Figure 11 - experimental results of imep versus timing for peak rate of heat release for DME-in-methane

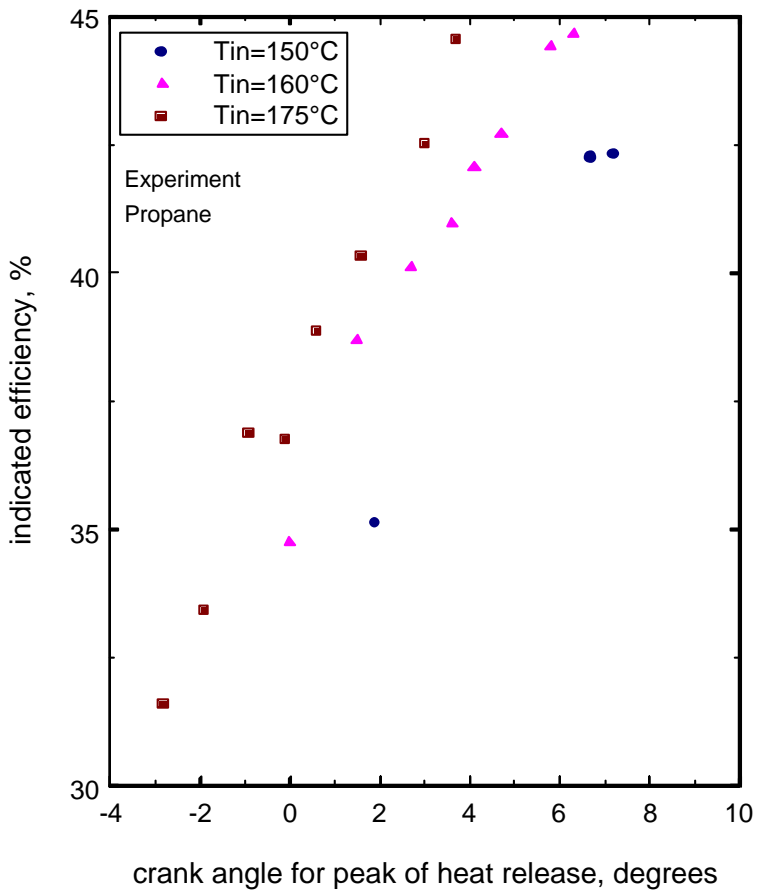

Figure 12 - experimental results of indicated efficiency versus timing for peak rate of heat release for propane

Figure 16 shows the carbon monoxide $(\mathrm{CO})$ in exhaust for the DME-in-methane tests. CO measurements were not available during the propane tests. The trend in the carbon monoxide is initially to decrease as peak heat release occurs later, and then to increase after a minimum value. The authors speculate that exhaust $\mathrm{CO}$ is a result of incomplete combustion in intermediate 
temperature regions where the $\mathrm{OH}$ radical concentration becomes significantly diminished resulting in less conversion of $\mathrm{CO}$ to $\mathrm{CO}_{2}$. For earlier combustion the charge is hotter overall and the mass in the intermediate temperature regions may be less, but more carbon is available because of increased equivalence ratio. As the combustion occurs later, the charge is cooler overall and the mass in the intermediate temperature regions is greater, resulting in greater concentration of $\mathrm{CO}$.

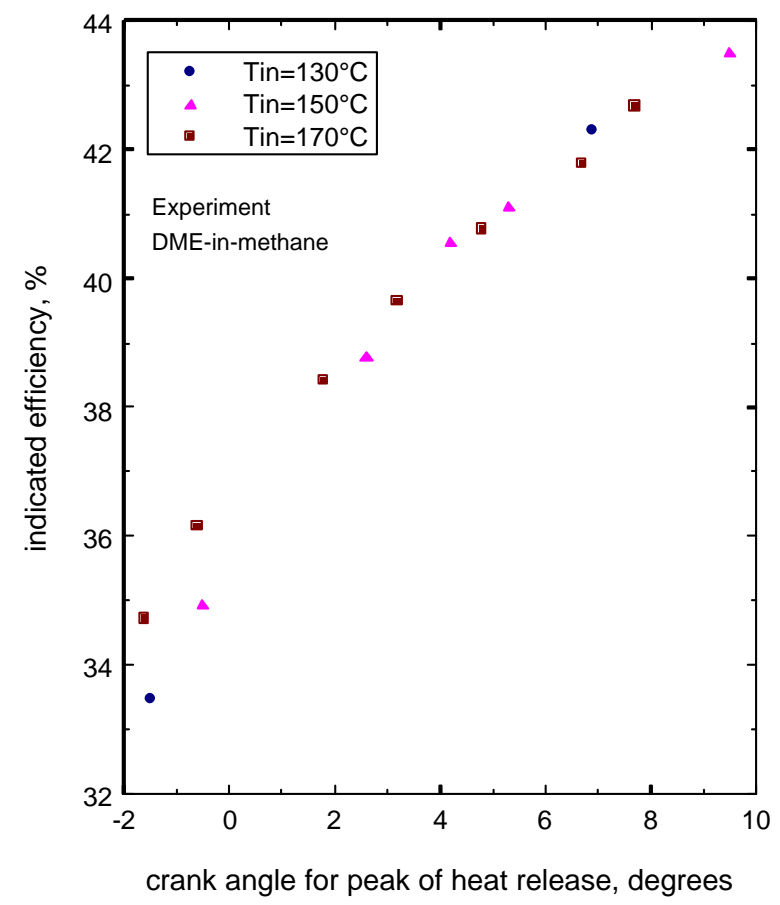

Figure 13 - experimental results of indicated efficiency versus timing for peak rate of heat release for DME-in-methane

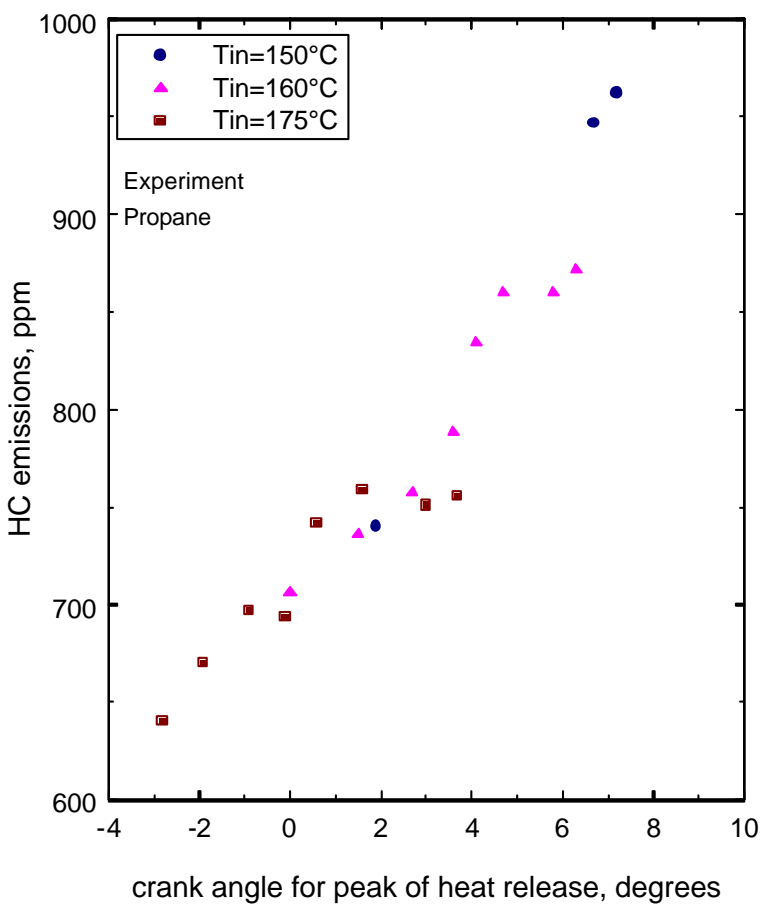

Figure 14 - experimental results of hydrocarbon emission versus timing for peak rate of heat release for propane

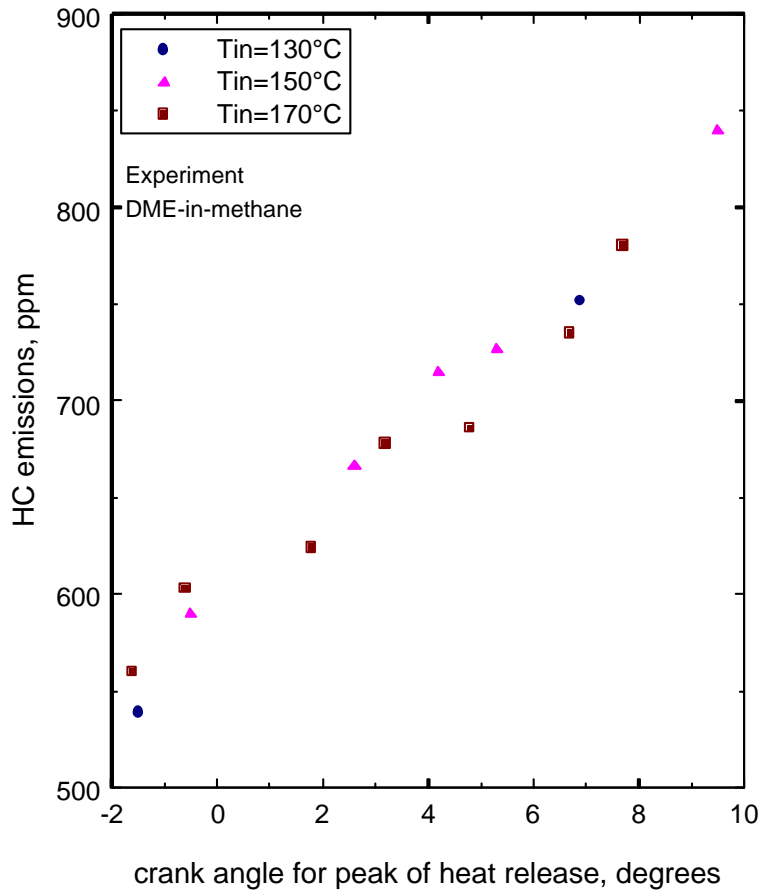

Figure 15 - experimental results of hydrocarbon emission versus timing for peak rate of heat release for DME-in-methane

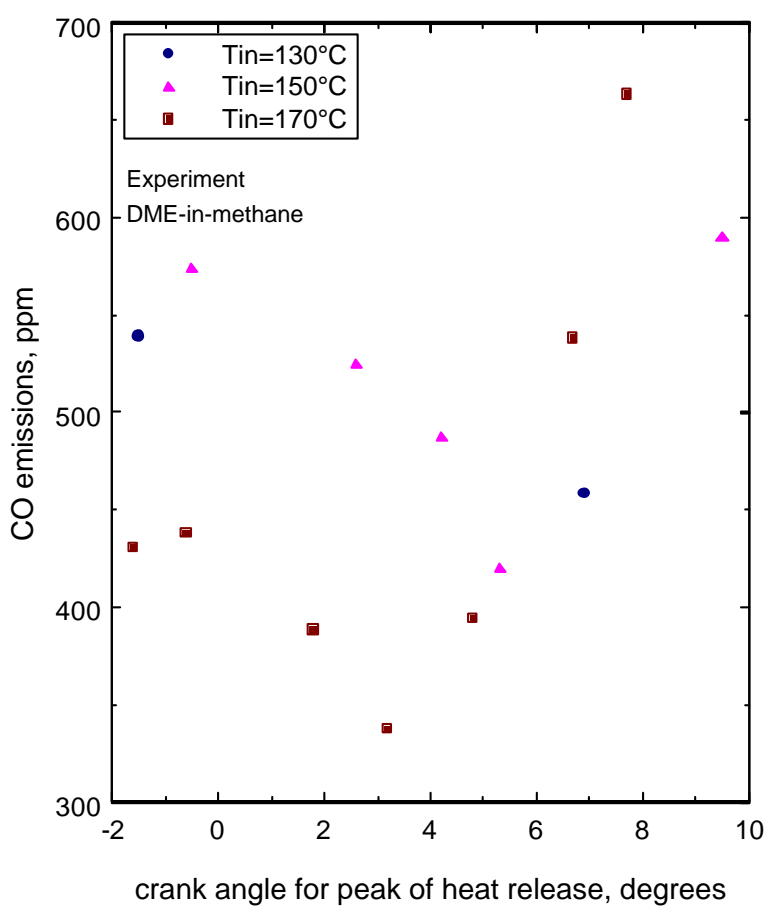

Figure 16 -experimental results of $\mathrm{CO}$ emissions versus timing for peak rate of heat release for DME-in-methane

Figures 17 and 18 show oxides of nitrogen $\left(\mathrm{NO}_{\mathrm{x}}\right)$ emission versus timing of peak of heat release rate. The results indicate the increase in emissions as the heat release advances due to higher peak temperatures due to higher equivalence ratio. For lower intake temperature, higher equivalence ratio is needed to 
achieve the same combustion timing, resulting in higher $\mathrm{NO}_{x}$ at the same timing as the intake temperature is reduced. $\mathrm{NO}_{\mathrm{x}}$ levels of less than 1 to $10 \mathrm{ppm}$ can be achieved with late combustion.

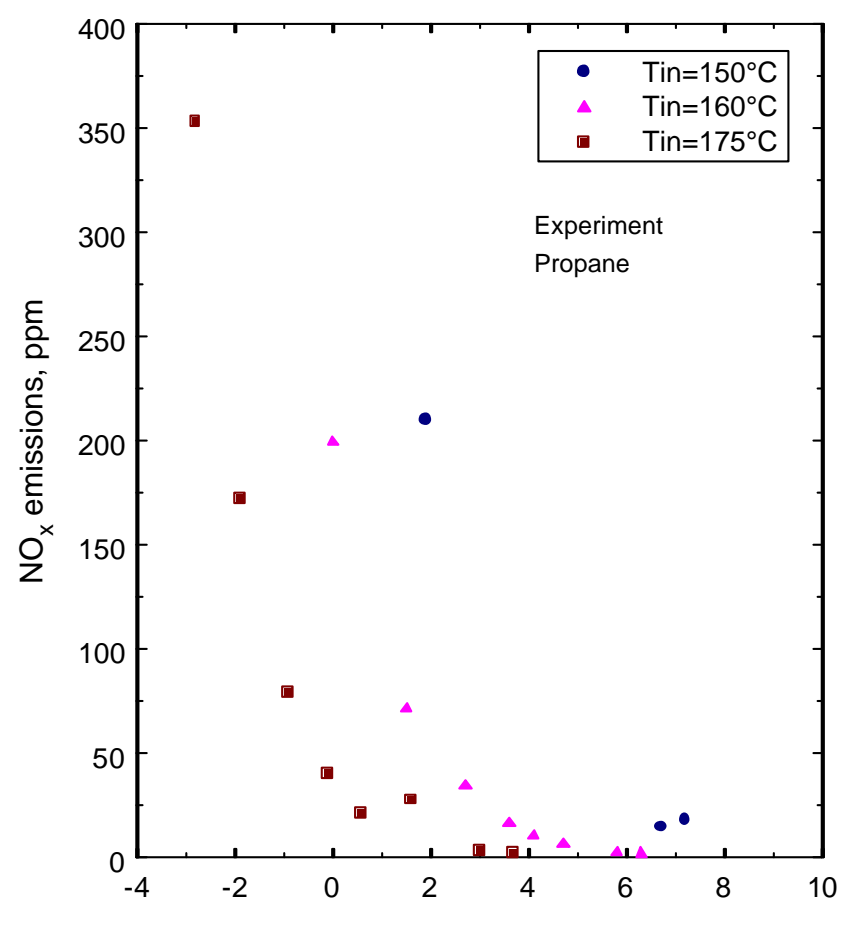

crank angle for peak of heat release, degrees

Figure 17 - experimental results of $\mathrm{NO}_{x}$ emissions versus timing of peak rate of heat release for propane

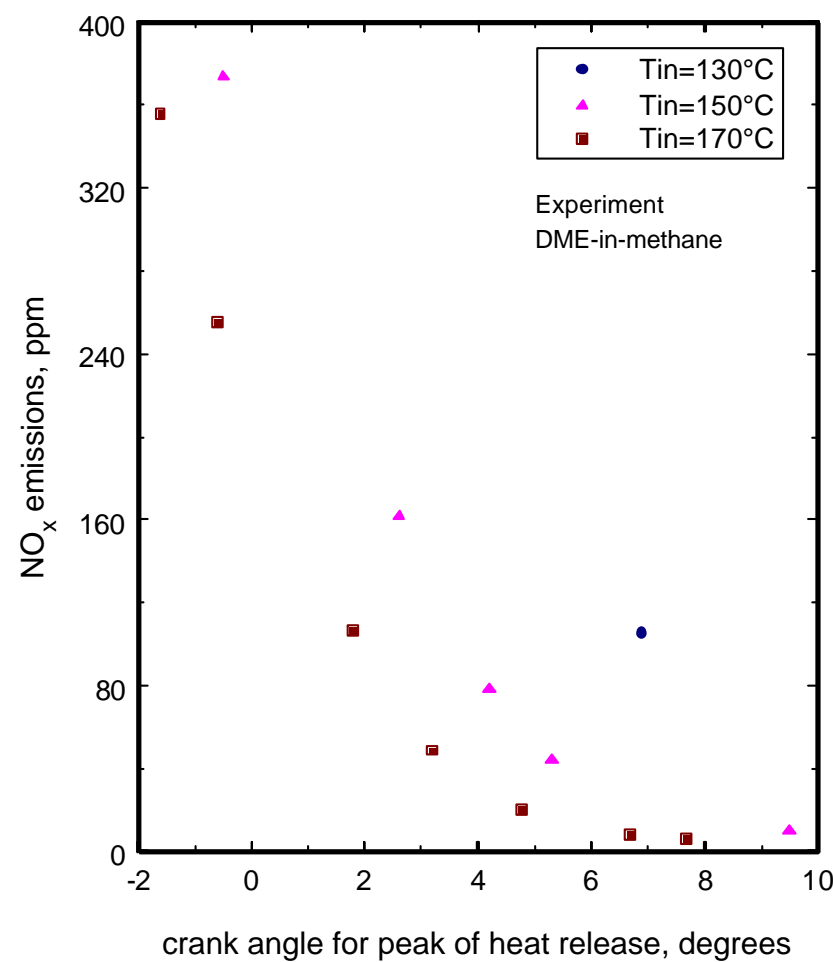

Figure 18 - experimental results of $\mathrm{NO}_{x}$ emissions versus timing of peak rate of heat release for DME-in-methane

\section{SIMULATION OF HCCI COMBUSTION}

All of the modeling computations in this study were carried out using the HCT model (Hydrodynamics, Chemistry and Transport) [17]. This model has been used in a large number of investigations over the years, and in particular was used in past studies of engine knock and autoignition [18][19][20]. The HCT code permits the use of a variety of boundary and initial conditions for reactive systems, depending on the needs of the particular system being examined. In the present case, the relevant conditions are those which describe the bulk gases in the combustion chamber.

Autoignition of a homogeneous charge is virtually identical to the knock process that can occur in the Otto cycle engine. From detailed kinetic modeling of motored engines studies of homogeneous charge with a variety of fuels, it is known that the controlling parameters in the initiation of this autoignition process are the fuel components (mixtures behave differently than neat fuels), and the temperature and density history that the fuel air mixture experiences. Motored engine experiments at General Motors Research Laboratories agree well with HCT simulation of this process. Thus if the precise conditions at the start of compression are known (species, temperature and pressure), the subsequent autoignition can be accurately predicted [21][19].

During an engine cycle, a number of processes occur which influence the time variation of the temperature and pressure of the bulk reactive gases in the combustion chamber. Piston motion first compresses and heats the bulk gases and then expands and cools them. During this time chemical reactions release heat and change the overall composition of the gases. Fresh unreacted fuel and air are added to hot residual gases left over from the previous cycle. Residual gases from previous engine cycles, which consist largely of water vapor, $\mathrm{CO} 2$, and molecular nitrogen and oxygen are assumed fully mixed with the fresh charge. In addition, heat losses to the engine chamber walls, blowby, fuel trapping in crevice volumes, and other processes can occur. However, in the current simulations only heat transfer losses are taken into account.

The computational model treats the combustion chamber as a homogeneous reactor with a variable volume. The mixed temperature of the residual gases and the fresh charge is estimated by a published procedure [15]. The volume is changed with time using a slider-crank formula. The heat transfer submodel employed in the HCT code simulations uses Woschni's correlation [16].

The present analysis considers a single zone, lumped model that ignores spatial variations in the combustion chamber, treating heat loss as a distributed heat transfer rate, proportional to the temperature difference between the average gas temperature and a time-averaged wall temperature. The authors recognize that this is a great 
oversimplification of the actual condition within the combustion chamber. In particular, the boundary layer, which contains significant mass, must be at a lower temperature than the bulk gas near TDC. Due to the assumed temperature uniformity our estimates of burn duration and the heat release processes, will be shorter than in experiments. That is, the boundary layer and crevices will always react last and extend the heat release rate compared to this simulation. Peak cylinder pressure and rate of pressure rise are thus overestimated with the current single-zone model, and the model cannot accurately predict $\mathrm{CO}$ and hydrocarbon emissions, which primarily depend on crevices and wall boundaries. Predictions of start of combustion and NO, which depend on the peak temperature of the core gases inside the cylinder, have been shown to be determined with reasonable accuracy [11].

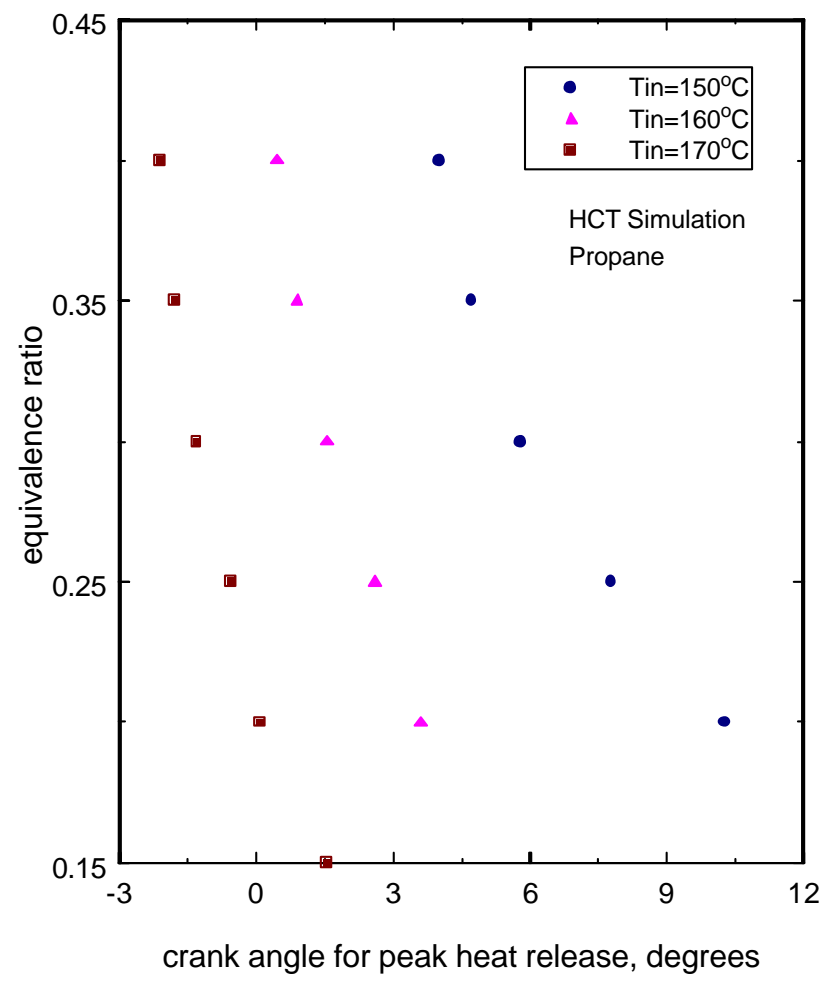

Figure 19 - simulation results of equivalence ratio versus peak of heat release for propane

Two reaction mechanisms are used in this study. The first mechanism, with 179 species and 1125 reactions, models natural gas autoignition chemistry [21]. The second mechanism is a reduced set with 102 species and 463 reactions models methane and dimethyl ether (DME) oxidation chemistry [22]. The 179 species mechanism includes species through $\mathrm{C}_{4}$ and the 102 species mechanism includes species through $\mathrm{C}_{2}$. Both mechanisms include $\mathrm{NO}_{x}$ kinetics from the Gas Research Institute mechanism version 1.2 [23]. The chemical kinetic reaction mechanisms used by the model for natural gas ignition and $\mathrm{NO}_{\mathrm{x}}$ production have been extremely well established and are widely used.
The simulation is started at BDC where fresh charge at specified pressure, temperature and composition is inducted into the cylinder. If EGR is used, the proper fraction of major residual gas components is added. The cylinder wall, piston and head are all assumed to be at a uniform $430 \mathrm{~K}$. Chemical reactions are computed explicitly in the kinetics model. Thermodynamic table values of $c_{p}$ and $c_{v}$ are explicitly calculated to account for enthalpy and pressure changes. The simulation is stopped at BDC and the indicated efficiency is computed. The $\mathrm{NO}_{x}$ values reported are taken at BDC.

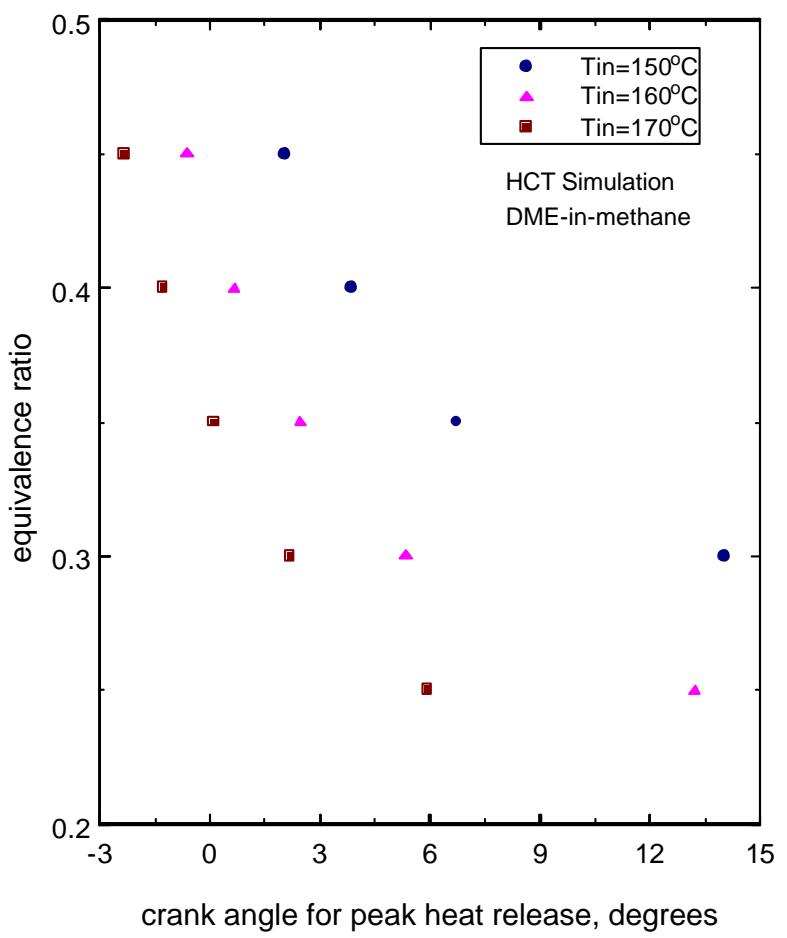

Figure 20 - simulation results of equivalence ratio versus peak of heat release for DME-in-methane

$\mathrm{HCT}$ can be used to model $\mathrm{HCCl}$ combustion in both single zone, well-stirred reactor, and in a multi-zone configuration, with thermally distributed zones. Multizone model captures much more of the detailed physics of the $\mathrm{HCCl}$ combustion process by accounting for cooler regions such as boundary layers and crevices. The single zone model treats the combustion chamber as being at uniform pressure and temperature throughout the volume. While multi-zone simulation yields more detail into the overall combustion process (particularly in prediction of hydrocarbon and $\mathrm{CO}$ emissions), it is significantly more expensive computationally, requiring two orders of magnitude more run time. A detailed description of this multi-zone method is available in the literature [14]. The single zone simulation results are representative of the charge core and are useful in predicting the effect of operating parameters on start of combustion, work, efficiency, and $\mathrm{NO}_{x}$ emissions. The single zone model will overpredict these quantities because slower or non-reacting regions 
such as walls and boundary that tend to slow down the burn are neglected.

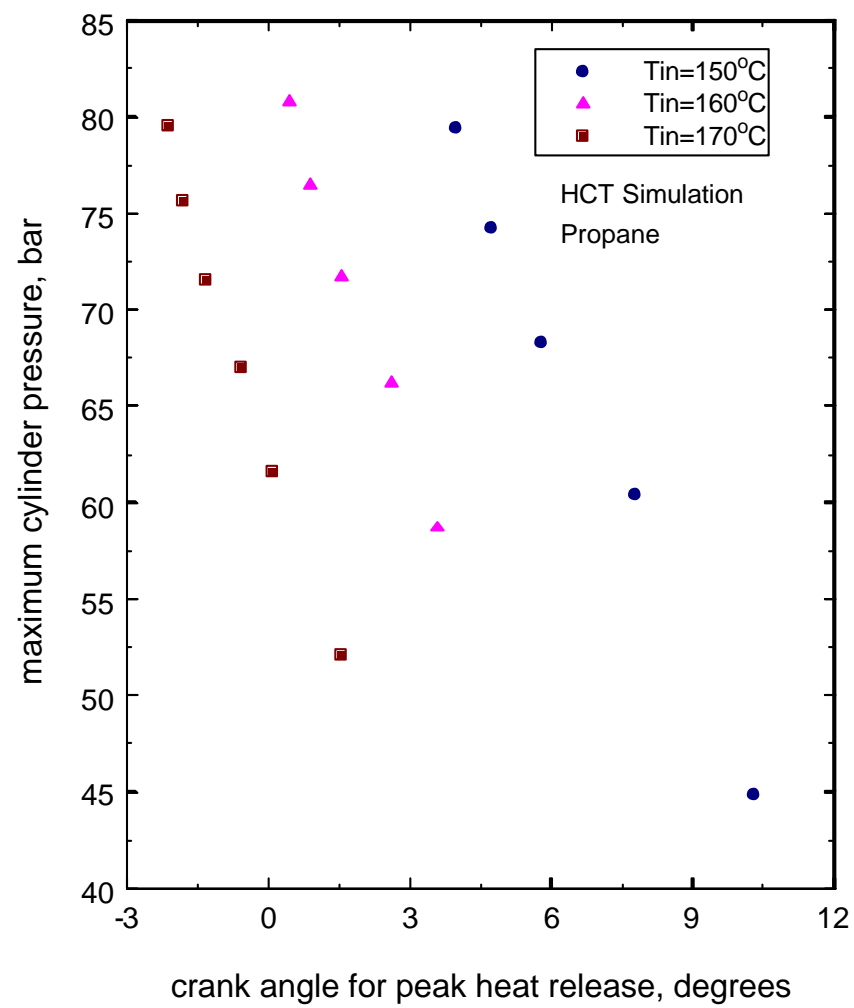

Figure 21 - simulation results of peak pressure versus peak of heat release for propane

\section{SINGLE ZONE SIMULATION OF CFR HCCI COMBUSTION}

The single zone model has been used to simulate the $\mathrm{HCCl}$ combustion process in the CFR engine. The 102 species mechanism is used to model the chemistry for the DME-in-methane blend and the 179 species mechanism has been used to model the propane chemistry. The operating parameters used in the simulation are the same as specified in Table 1. For each operating point the simulation requires roughly 45 seconds of CPU time for the 102 species mechanism and roughly 3 minutes of CPU time for the 179 species mechanism on a single processor of a Compaq AlphaServer 4100 5/533.

Residual gas, with a fraction corresponding to the clearance volume of the cylinder, is mixed with the displaced volume of fresh charge. The heat transfer correlation requires specification of the wall temperature. The wall temperature must be specified for the heat transfer correlation and is set at a constant value of $157^{\circ} \mathrm{C}$.

The results for equivalence ratio, imep, indicated efficiency, maximum cylinder pressure, and $\mathrm{NO}_{x}$ emissions versus the timing for peak rate of heat release are shown in Figures 19 through 28. For both fuels, the propane and the DME-in-methane blend, the results for $\mathrm{HCCl}$ operation has been simulated for intake temperatures of $150^{\circ} \mathrm{C}, 160^{\circ} \mathrm{C}$, and $170^{\circ} \mathrm{C}$. These simulations are not designed to be a direct validation of the experimental data, because the initial conditions in the engine are not well established here. These results show trends consistent with the experimental data in the general trends with respect to intake temperature. The predicted efficiency shows an overall increase as the peak of heat release occurs later. The imep shows a decline with later timing that is consistent with only part of the trend of imep shown in the experiments. As mentioned previously, this inconsistency can be explained as being due to increased heat transfer in higher equivalence ratio. The $\mathrm{NO}_{\mathrm{x}}$ trend is very consistent as it depends principally on the peak temperature during the cycle. Accurately modeling engine heat transfer characteristics is very important in modeling the $\mathrm{HCCl}$ combustion process correctly.

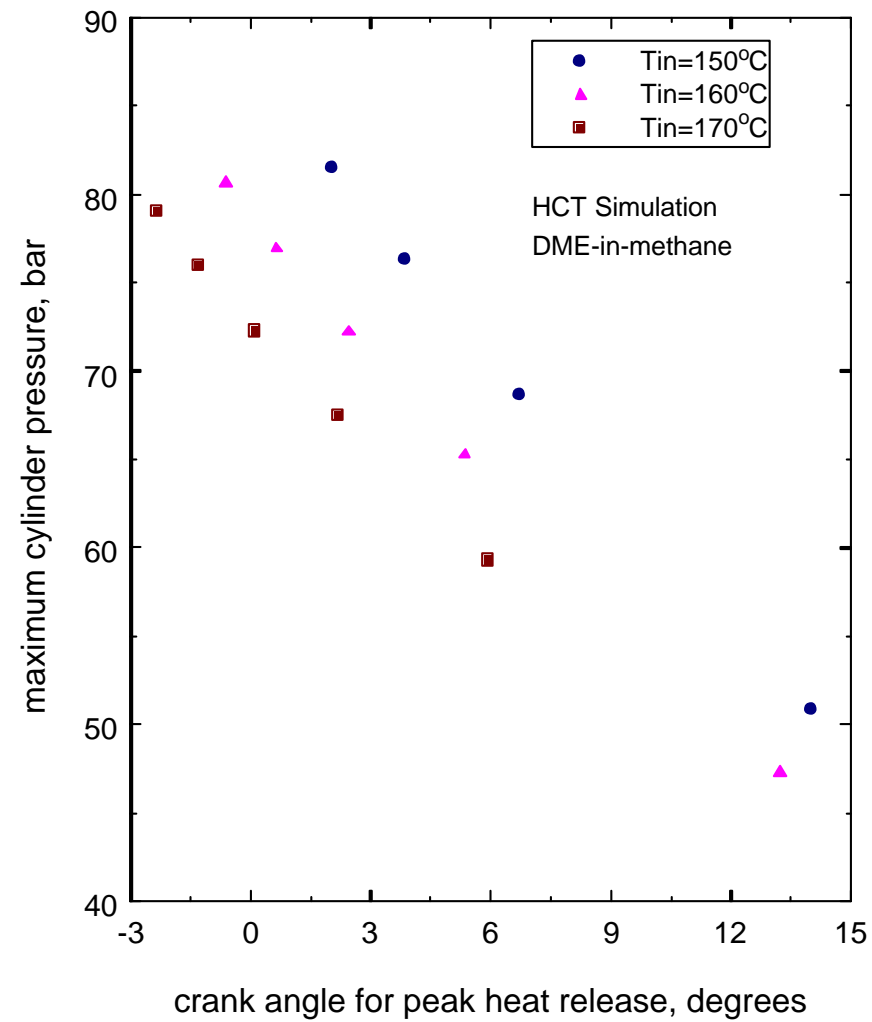

Figure 22 - simulation results of peak pressure versus peak of heat release for DME-in-methane

The experimental results show that the burn duration can become significantly longer as the combustion timing occurs later and later in the cycle. Single zone modeling has been performed to further investigate this phenomenon. The 102 species methane and DME reaction mechanism has been used in this HCT simulation of the CFR engine. The 15\% DME-inmethane blend is studied for equivalence ratio ranging from 0.25 to 0.4 . Figure 29 shows the rate of heat release versus crank angle for four different equivalence 
ratios. This mixture is very extreme with a very high cetane number fuel (DME), and very low cetane number (methane). The heat release is clearly bimodal, and as the equivalence ratio decreases and the timing moves later and later the separation between the primary heat release and the secondary heat release becomes much larger. It is also apparent that the burn duration becomes much longer as ignition occurs later in the cycle.

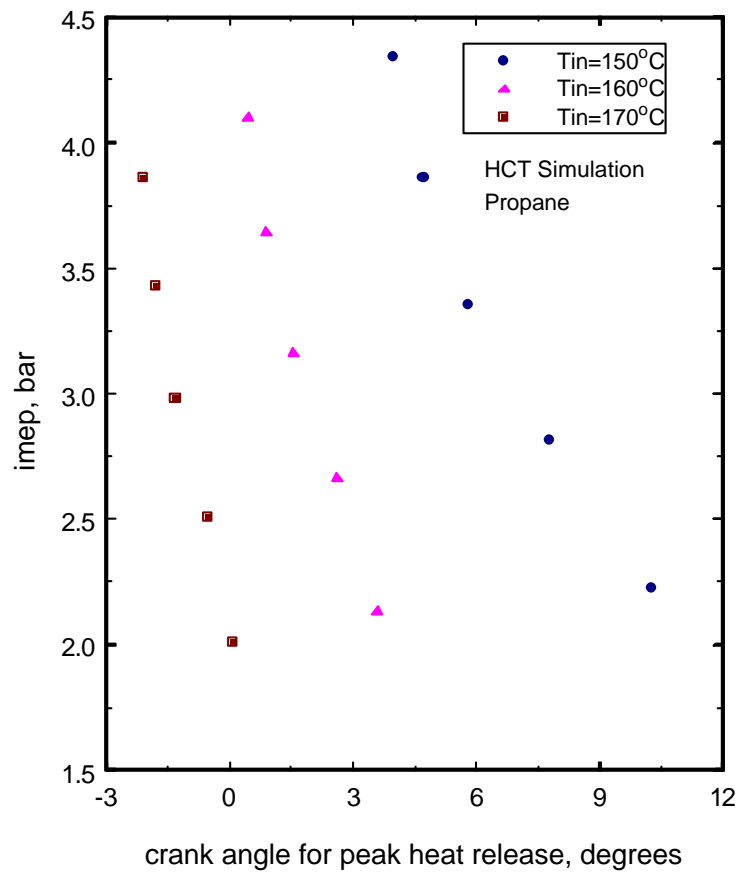

Figure 23 - simulation results of imep versus peak of heat release for propane

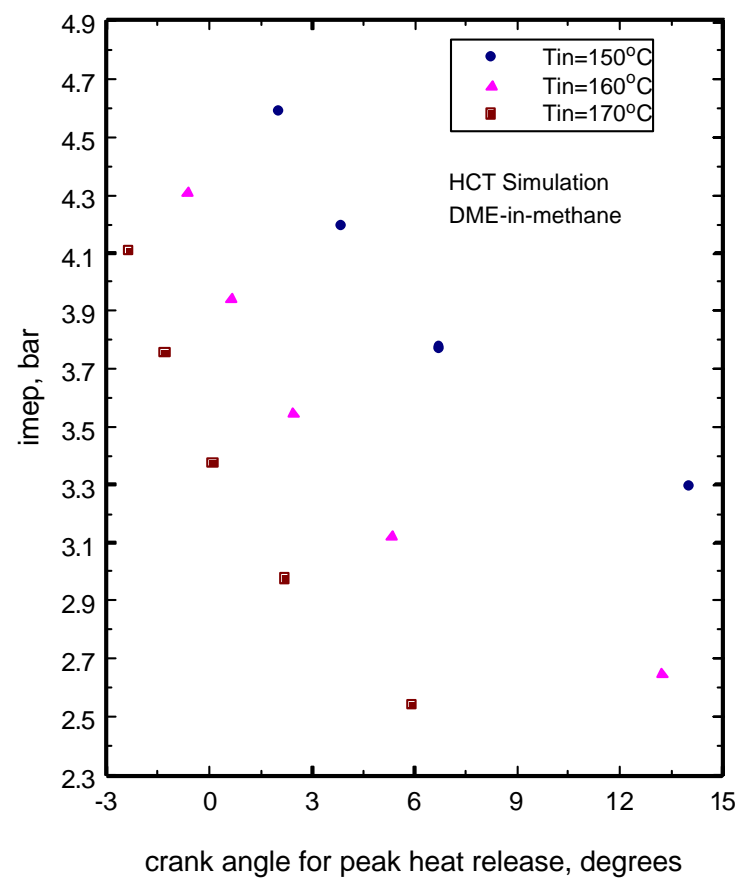

Figure 24 - simulation results of imep versus peak of heat release for DME-in-methane

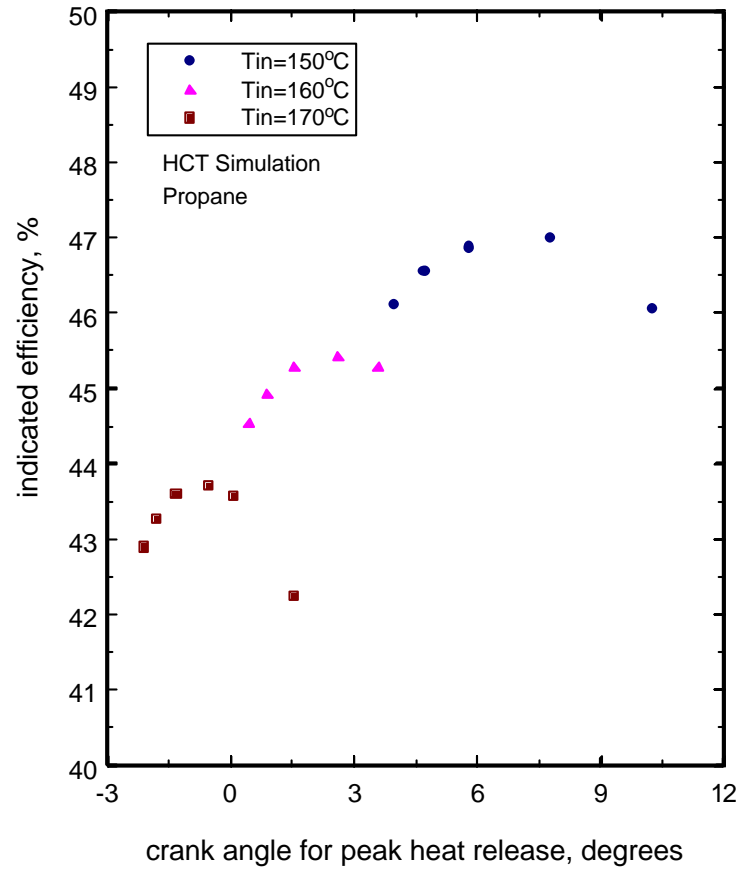

Figure 25 - simulation results of efficiency versus peak of heat release for propane

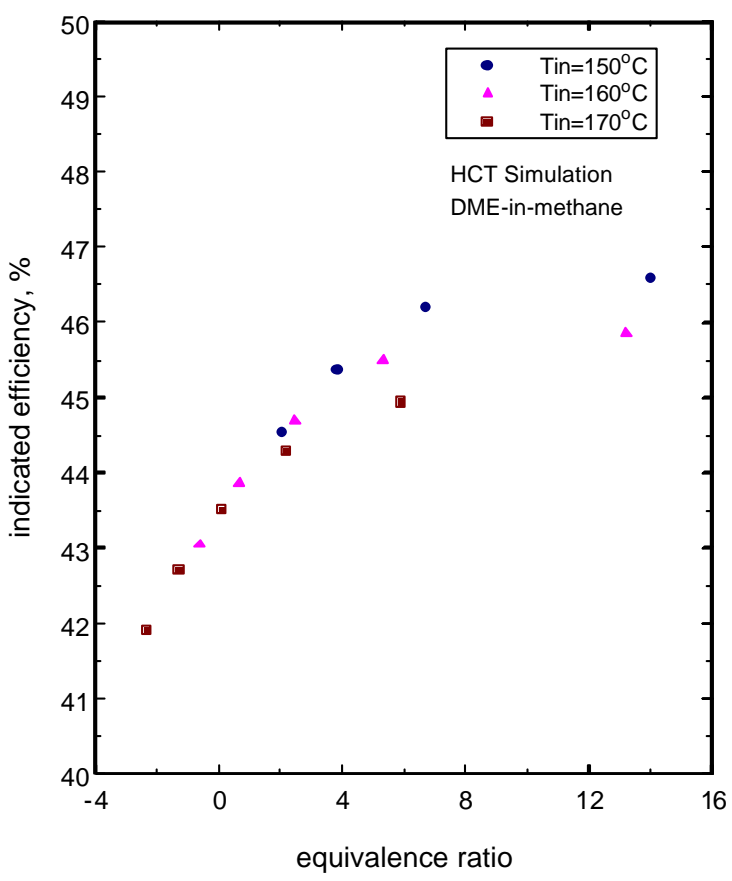

Figure 26 - simulation results of efficiency versus peak of heat release for DME-in-methane

Figure 30 shows the fraction of each species consumed for the four different equivalence ratios. This figure shows that with decreasing equivalence ratio, the timing for the consumption of the DME delays gradually, while the timing for the consumption of methane becomes significantly later as the equivalence ratio is reduced. The response of individual components in multicomponent fuels can significantly affect the heat release process. As most practical fuels contain several 
components (gasoline, commercial propane, natural gas) variations in the ignition and heat release process due to component chemistry should be considered.

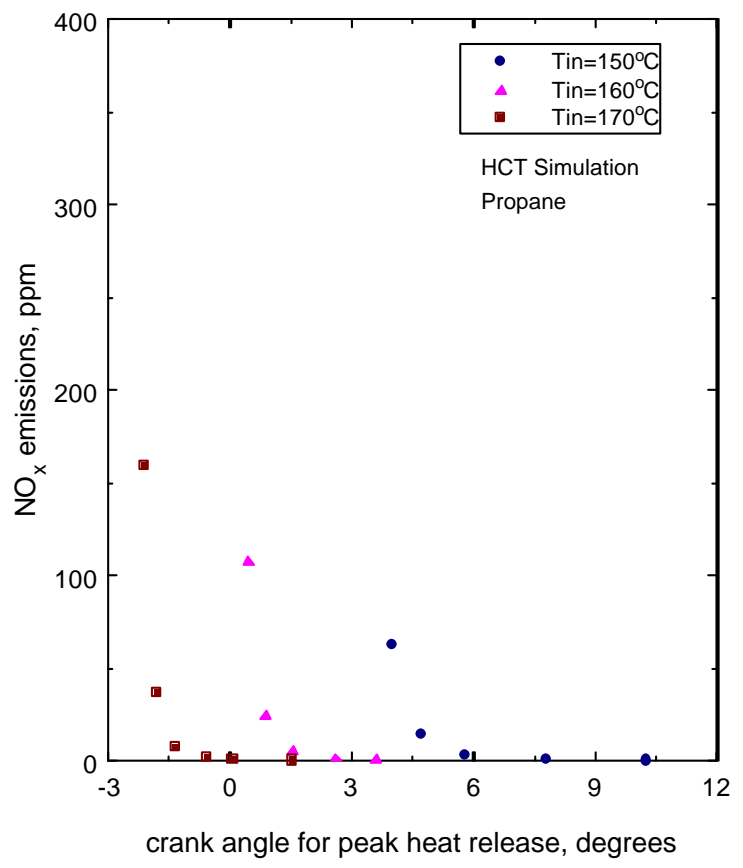

Figure 27 - simulation results of $\mathrm{NO}_{x}$ emissions versus peak of heat release for propane

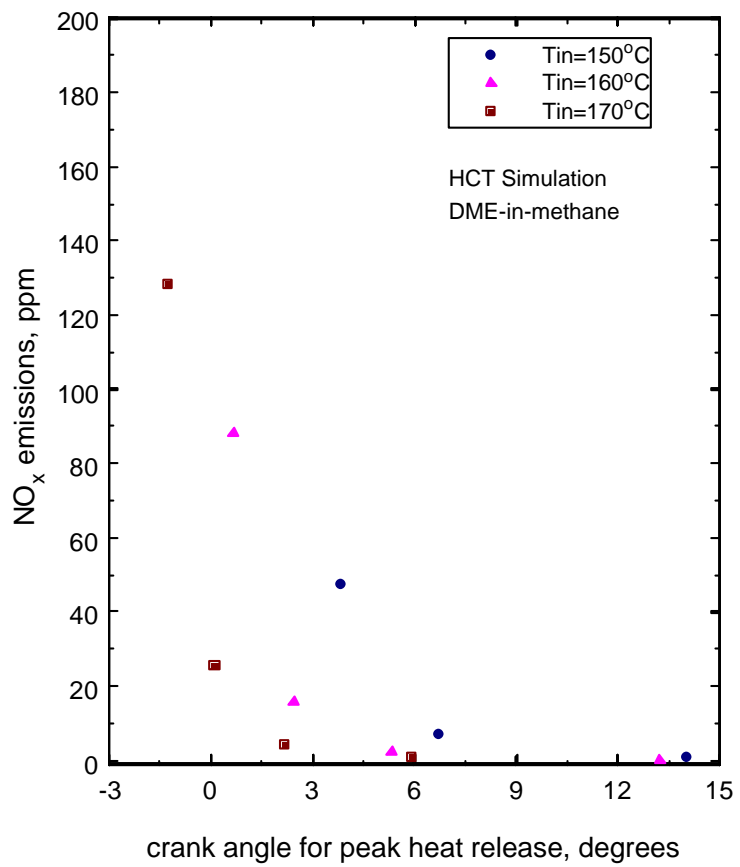

Figure 28 - simulation results of $\mathrm{NO}_{x}$ emissions versus peak of heat release for DME-in-methane

The experimental and simulation results provide fundamental information related to control of $\mathrm{HCCl}$ engine combustion timing. In practical operation selection of the operating points may require considering a tradeoff between efficiency, which is shown to consistently increase with delayed timing, and output power, which generally is maximized near TDC. The compensation variable that is related to engine control in this case is intake temperature. For a thermally controlled engine the load and efficiency should be considered with respect to intake temperature, and then the temperature and equivalence ratio would be selected to meet the load requirement with highest efficiency. Emission constraints would also be incorporated into the operating point selection process.

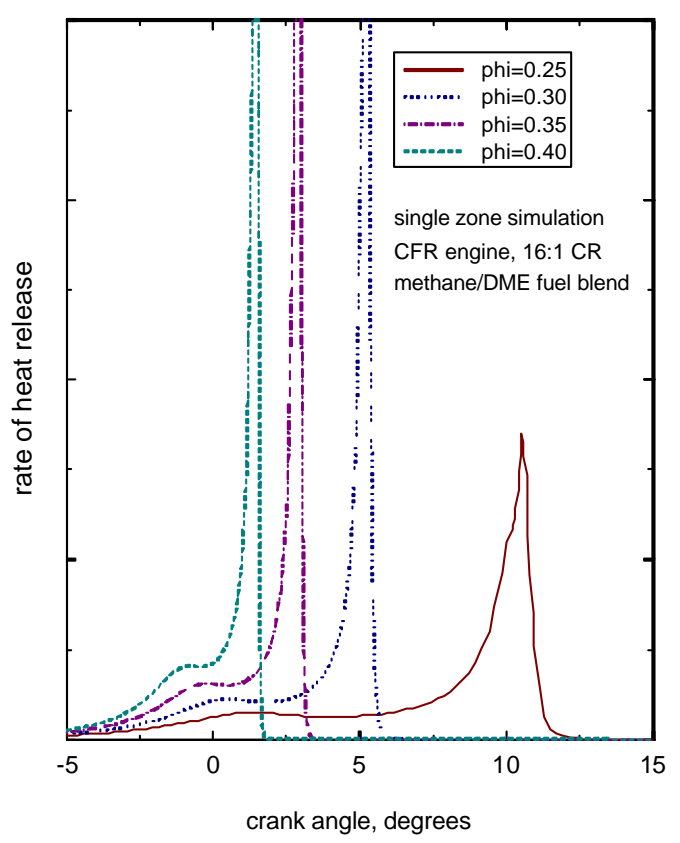

Figure 29 - simulation results of heat release versus crank angle for several equivalence ratios with a DME-in-methane fuel blend

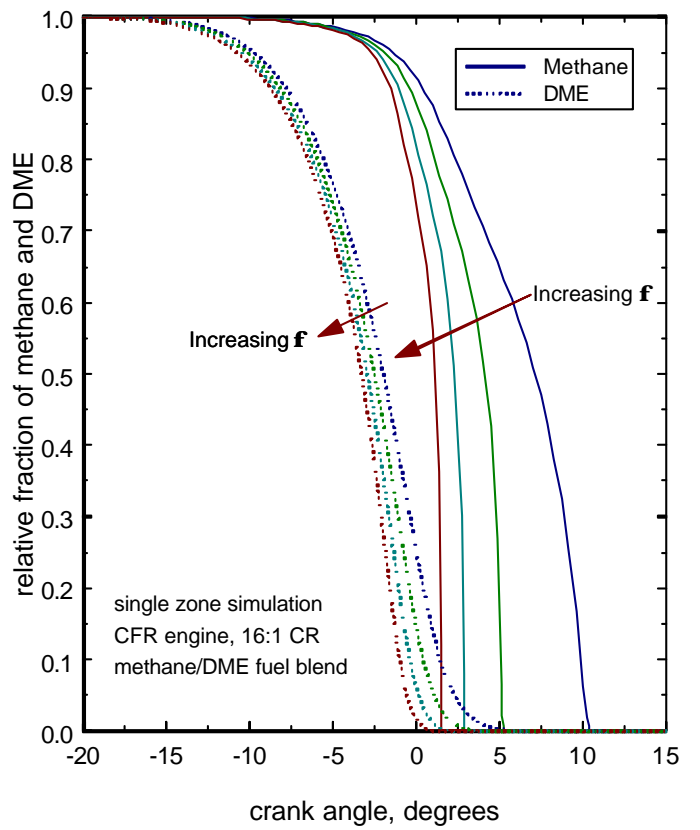

Figure 30 - simulation results of component fuel consumption versus crank angle for several equivalence ratios with a DME-in-methane fuel blend 


\section{CONCLUSIONS}

A single cylinder CFR engine has been modified to operate in $\mathrm{HCCl}$ mode. Neat propane and a DME-inmethane blend have been studied over a range of equivalence ratio from 0.2 to 0.4 for several different intake temperatures and at constant engine speed. Experiments have been performed to study the effects of combustion timing on the $\mathrm{HCCl}$ combustion process. The results demonstrate that indicated efficiency increases as the combustion timing is delayed. The imep tends to decrease as the timing is delayed. Hydrocarbon emissions increase with later combustion timing, while $\mathrm{NO}_{\mathrm{x}}$ emissions become very low with later combustion. Simulation of $\mathrm{HCCl}$ combustion has been performed using the single zone HCT model. An HCT single zone chemical kinetics model shows trends similar to the experimental results in looking the relationship between combustion timing, equivalence ratio, efficiency, imep, and $\mathrm{NO}_{x}$ emissions. The single zone model was used to evaluate the bimodal nature of heat release in a two component fuel. The kinetics of the mixture of a very high cetane number fuel and a low cetane number fuel show a two-stage heat release, particularly as the combustion timing moves later.

\section{ACKNOWLEDGMENTS}

This project is funded by DOE Office of Advanced Automotive Technologies, Steve Chalk and Lucito Cataquiz, Program Managers and the DOE office of Heavy Vehicle Technology, Steve Goguen and Gurpreet Singh, Program Managers. Work performed under the auspices of the U.S. Department of Energy by Lawrence Livermore National Laboratory under Contract W-7405ENG-48.

\section{REFERENCES}

1. Suzuki, H., Koike, N., Ishii, H., and Odaka, M., 1997, "Exhaust Purification of Diesel Engines by Homogeneous Charge with Compression Ignition Part 1: Experimental Investigation of Combustion and Exhaust Emission Behavior Under Pre-Mixed Homogeneous Charge Compression Ignition Method," SAE paper 970313.

2. Onishi, S., Jo, S. H., Shoda, K., Jo, P. D., and Kato, S., 1979, "Active Thermo-Atmosphere Combustion (ATAC) - A New Combustion Process for Internal Combustion Engines," SAE paper 790501

3. Noguchi, M., Tanaka, Y., Tanaka, T., and Takeuchi, Y., 1979,"A Study on Gasoline Engine Combustion by Observation of Intermediate Reactive Products During Combustion," SAE paper 790840.

4. Ishibashi, Y., and Asai, M., 1996, "Improving the Exhaust Emissions of Two-Stroke Engines by Applying the Activated Radical Concept," SAE Paper 960742.

5. Ishibashi, Y., and Asai, M., 1998, "A Low Pressure Pneumatic Direct Injection Two-Stroke Engine by
Activated Radical Combustion Concept," SAE Paper 980757.

6. Najt, P. M. and Foster, D. E., 1983, "CompressionIgnited Homogeneous Charge Combustion," SAE paper 830264.

7. Smith, J.R., Aceves, S.M., Westbrook, C. and Pitz, W., 1997,"Modeling of Homogeneous Charge Compression Ignition ( $\mathrm{HCCl})$ of Methane," Proceedings of the 1997 ASME Internal Combustion Engine Fall Technical Conference, Paper No. 97-ICE68, ICE-Vol. 29-3, pp. 85-90.

8. Willand, J., Nieberding, R. -G., Vent, G., and Enderle, C., 1998, "The Knocking Syndrome - Its Cure and Potential," SAE paper 982483.

9. Amsden, A.A., 1993, "KIVA-3: A KIVA Program with Block-Structured Mesh for Complex Geometries," Los Alamos National Laboratory Report LA-12503MS.

10. Miyamoto, T., Hayashi, A. K., Harada, A., Sasaki, S., Hisashi, A., and Tujimura, K., 1999, "A Computational Investigation of Premixed Lean Diesel Combustion," SAE paper 1999-01-0229.

11. Aceves, S., Smith, J. R., Westbrook, C, and Pitz, W., 1999, "Compression Ratio Effect on Methane $\mathrm{HCCl}$ Combustion," ASME Journal of Gas Turbines and Power, in press.

12. Christensen, M., Johansson, B., Amneus, P., and Mauss, F., 1998, "Supercharged Homogeneous Charge Compression Ignition," SAE Paper 980787.

13. Flowers, D. L., Aceves, S. M., Westbrook, C. K., Smith, J.R., and Dibble, R. W., 1999, "Sensitivity of natural gas $\mathrm{HCCl}$ combustion to fuel and operating parameters using detailed kinetic modeling," Proceedings of the Advanced Energy Systems Division, ASME 1999 International Mechanical Engineering Congress and Exposition.

14. Aceves, S.M, Flowers, D. L., Westbrook, C. K., Smith, J. R., and Dibble, R. W., 2000, "A Multizone Simulation of $\mathrm{HCCl}$ combustion and Emissions," SAE paper 2000-01-0327.

15. Heywood, J. B., 1988, Internal Combustion Engine Fundamentals, McGraw-Hill, Inc., New York, NY

16. Woschni, G., 1967, "Universally Applicable Equation for the Instantaneous Heat Transfer Coefficient in the Internal Combustion Engine," SAE Paper 670931

17. Lund, C. M., 1978 "HCT - A General Computer Program for Calculating Time-Dependent Phenomena Involving One-Dimensional Hydrodynamics, Transport, and Detailed Chemical Kinetics," Lawrence Livermore National Laboratory report UCRL-52504.

18. Westbrook, C. K., Pitz, W. J., and Leppard, W. R., 1991, "The Autoignition Chemistry of Paraffinic Fuels and Pro-Knock and Anti-Knock Additives: A Detailed Chemical Kinetic Study," SAE paper 912314.

19. Pitz, W. J., Westbrook, C. K., and Leppard, W. R., 1991, "Autoignition Chemistry of C4 Olefins Under Motored Engine Conditions: A Comparison of Experimental and Modeling Results,"SAE paper 912315. 
20. Westbrook, C. K., Warnatz, J., and Pitz, W. J., 1988, "A Detailed Chemical Kinetic Reaction Mechanism for the Oxidation of iso-Octane and n-Heptane over an Extended Temperature Range and its Application to Analysis of Engine Knock," Twenty-Second Symposium (International) on Combustion, p. 893, The Combustion Institute, Pittsburgh.

21. Curran, H. J., Gaffuri, P., Pitz, W. J., Westbrook, C. K., and Leppard, W. R., 1995, "Autoignition Chemistry of the Hexane Isomers: An Experimental and Kinetic Modeling Study," SAE paper 952406.
22. Curran, H. J., Pitz, W. J., Marinov, N. M., and Westbrook, C. K., 1997, "A Wide Range Modeling Study of Dimethyl Ether Oxidation," Lawrence Livermore National Laboratory Report UCRL-JC127071.

23. Frenklach, M.,Wang, H., Goldenberg, M., Smith G. P., Golden, D. M., Bowman, C. T., Hanson, R. K., Gardiner, W. C., and Lissianski, V., 1995, "GRI-Mech - An Optimized Detailed Chemical Reaction Mechanism for Methane Combustion", GRI Topical Report No. GRI-95/0058. 

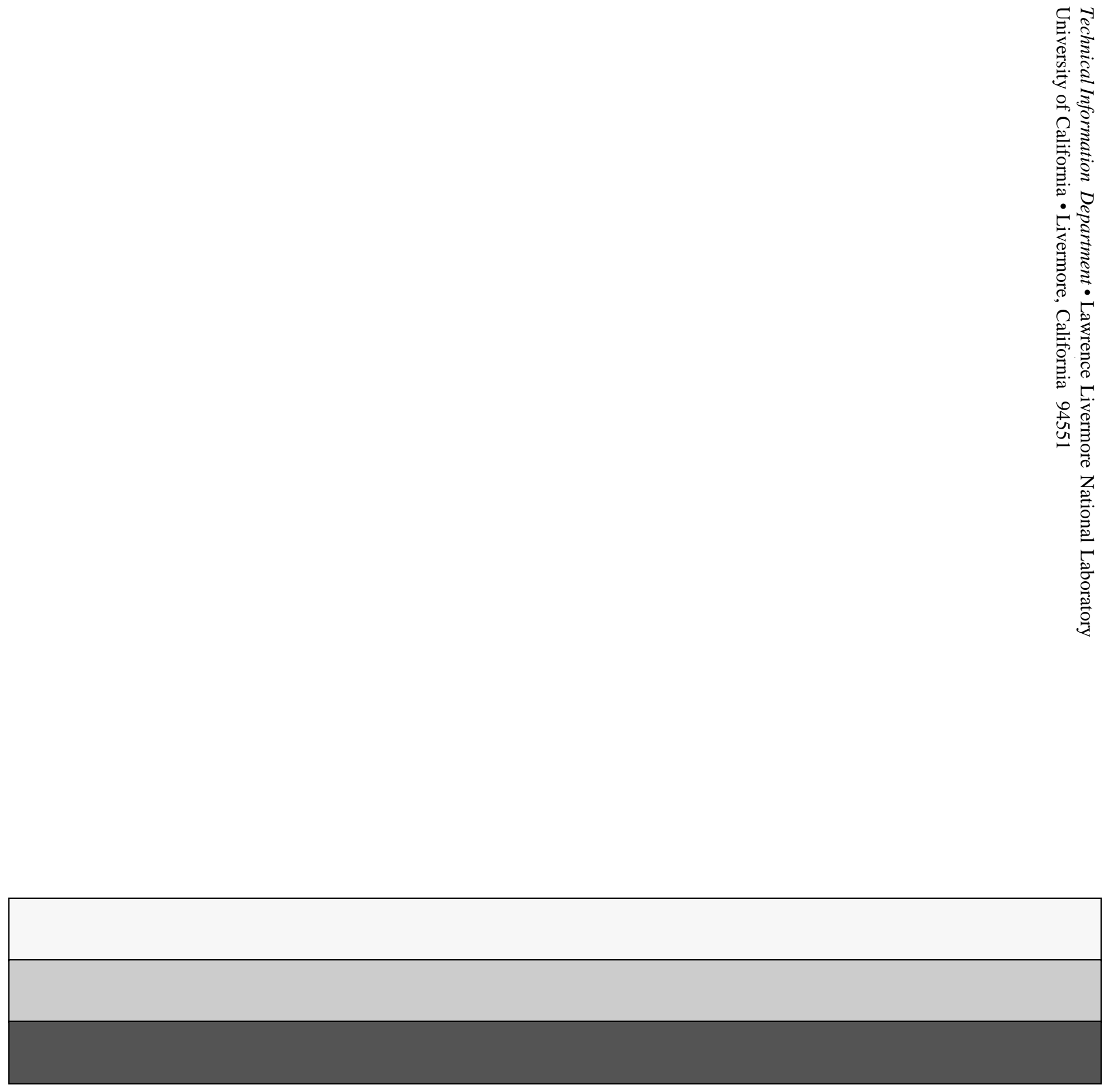